\title{
Association between SLC44A4-NOTCH4 SNPs and serum lipid levels in the Chinese Han and Maonan ethnic groups
}

\author{
Peng-Fei Zheng ${ }^{1}$, Rui-Xing Yin ${ }^{1,2,3^{*}}$ (D), Yao-Zong Guan ${ }^{1}$, Bi-Liu Wei ${ }^{1}$, Chun-Xiao Liu ${ }^{1}$ and Guo-Xiong Deng ${ }^{1}$
}

\begin{abstract}
Background: The current research was to assess the relationship of the solute carrier family 44 member 4 (SLC44A4) rs577272, notch receptor 4 (NOTCH4) rs3134931 SNPs and serum lipid levels in the Han and Maonan ethnic groups.

Methods: The genetic makeup of the SLC44A4 rs577272 and NOTCH4 rs3134931 SNPs in 2467 unrelated subjects (Han, 1254; Maonan, 1213) was obtained by using polymerase chain reaction and restriction fragment length polymorphism technique, combined with gel electrophoresis, and confirmed by direct sequencing.

Results: The genotype frequencies of SLC44A4 rs577272 and NOTCH4 rs3134931 SNPs were different between Han and Maonan populations ( $P<0.05$ ); respectively. The SLC44A4 rs577272 SNP was associated with total cholesterol (TC) and high-density lipoprotein cholesterol (HDL-C) levels in Maonan group. The NOTCH4 rs3134931 SNP was associated with triglyceride (TG) in Han; and TG and low-density lipoprotein cholesterol (LDL-C) levels in Maonan groups $(P<0.025-0.001)$. Stratified analysis according to gender showed that the SLC44A4 rs577272 SNP was associated with TC and HDL-C in Han and Maonan females; TC in Maonan males, meanwhile, the NOTCH4 rs3134931 SNP was associated with TG and HDL-C in Han males; TG in Han females; TG and LDL-C in Maonan males; and TG, HDL-C and LDL-C in Maonan females. Linkage disequilibrium analysis showed that the most common haplotype was rs577272Grs3134931 A (> 50\%) in both Han and Maonan groups. The haplotype of rs577272G-rs3134931A was associated with TG and HDL-C in Han; and TC, TG and HDL-C in Maonan ethnic groups.
\end{abstract}

Conclusions: These results suggest that the relationship among SLC44A4 rs577272, NOTCH4 rs3134931 SNPs and serum lipid parameters may vary depending on the gender and/or ethnicity/race in some populations. Haplotypes could explain more changes in serum lipid parameters than any single SNP alone particularly for TC, TG and HDL-C.

Keywords: Solute carrier family 44 member 4, Notch receptor 4, Single nucleotide polymorphism, rs577272, rs3134931, Haplotypes, Lipids

\section{Background}

Dyslipidemia is heritable risk factor of coronary heart disease (CHD), which has been a prominent reason of disability, mortality, morbidity, functional deterioration

\footnotetext{
*Correspondence: yinruixing@163.com

${ }^{1}$ Department of Cardiology, Institute of Cardiovascular Diseases, The First Affiliated Hospital, Guangxi Medical University, Nanning 530021, Guangxi, People's Republic of China

Full list of author information is available at the end of the article
}

and expensive healthcare, and accounts for approximately $30 \%$ of all the deaths worldwide [1-4]. Previous studies have shown that CHD occurs due to various factors and can be subjective to genomic background, lifestyle, environmental factors and alterations of plasma lipid levels as well as their interactions with each other [5, 6]. Coronary atherosclerosis is generally considered to be the pathological foundation of CHD [7], which is caused by the accumulation of cholesterol in arterial wall macrophages and the dysregulation of metabolic rate of lipids 
for example increased levels of total cholesterol (TC) [8], triglyceride (TG) [9], low-density lipoprotein cholesterol (LDL-C) [10], and apolipoprotein (Apo) B [11], along with reduced levels of ApoA1 [11] and high-density lipoprotein cholesterol (HDL-C) [12] in serum. Thus, it can be seen that hyperlipidaemia (HLP) acts as a crucial risk factor for CHD and its complications. HLP is deemed to be affected by various hereditary and environmental elements and their connections [13].

Previous genome-wide association studies (GWASes) have demonstrated that the rs577272 SNP near the Solute carrier family 44 member 4 gene (SLC44A4; also knows as: CTL4; NG22; TPPT; DFNA72; hTPPT1; C6orf29, GeneID:80736, HGNC ID: 13941, locus type: gene with protein product, located in chromosome 6p21.33) was associated with serum TC and C-reactive protein (CRP) levels, which are all risk factors for CHD [14]. At the same time, the rs3134931 SNP near the neurogenic locus notch homolog protein 4 gene (NOTCH4; also knows as: INT3, Gene ID: 4855, HGNC ID: 7884, locus type: gene with protein product, located in chromosome 6p21.32) may result in regulating serum myeloperoxidase (MPO) levels in Europeans [15]. Some researchers have demonstrated that serum levels of MPO are linked with the elevated risk of CHD by a mechanism inducing dysfunctional HDL particles [16] and MPO-dependent LDL oxidation [17]. Previous work has also demonstrated that endothelial $\mathrm{NOTCH}$ signaling is impacted by lipid-mediated inflammatory status, and its down-regulation seems to correlate with an inflammatory state in the endothelium, and all $\mathrm{NOTCH}$ receptors (NOTCH1-4) are expressed in the vascular system [18]. It is noticeable that $\mathrm{NOTCH} 4$ expression is significantly reduced in patients with HLP, NOTCH4 is a pathogenic factor involved in the process that lipids lead to vascular endothelial inflammation [19]. Nevertheless, the association among the SLC44A4 rs577272, NOTCH4 rs3134931 SNPs and serum lipid levels in Han and Maonan ethnic groups is not clear and not reported in literature.

China is well-known as a country with multiple ethnicities- that is composed of the Han nationality and 55 ethnic minorities. As per the sixth national census statistics of China (2010), the total population of the Maonan ethnic group was 107,166 (37th). Most of the Maonan people are located in Huanjiang Maonan Autonomous County, Guangxi Zhuang Autonomous Region. Although the population of Maonan is small, there are various differences in lifestyle and dietary habits between Maonan and local Han populations, the marriage custom in Maonan is relatively conservative. Maonan still maintain the custom of intra-ethnic marriages, thus, intermarriage with other ethnic groups is very rare [20]. Therefore, there was less diversity about their genetic background in Maonan population. As far as we know there has not been any previous study on the relationship among the SLC44A4 rs577272, NOTCH4 rs3134931 SNPs and serum lipid levels in the Han and Maonan ethnic groups. Thus, this study was designed to understand the relationship of the SLC44A4 rs577272, NOTCH4 rs3134931 SNPs and several environmental aspects with serum lipid levels in the Han and Maonan ethnic groups.

\section{Materials and methods \\ Study populations}

A total of 1254 (569 males, 45.37\%; 685 females, 54.63\%) unrelated participants of Han nationality and 1213 unrelated subjects (505 males, 41.63\%; 708 females, 58.37\%) of Maonan nationality were arbitrarily chosen based on our previously stratified randomized samples. All of the subjects were farm workers. They were staying in Huanjiang Maonan Autonomous County, Guangxi Zhuang Autonomous Region of China. They were in the age range of 16-88 years. There was not any difference in age distribution ( $57.58 \pm 12.94$ vs. $57.20 \pm 15.08)$ and gender ratio between Han and Maonan groups, respectively. The selection criteria for Maonan individuals have been described in detail in our previous epidemiological studies $[21,22]$. All subjects were basically healthy and none of them had a history of CHD, myocardial infarction (MI), ischemic stroke (IS) and type 2 diabetes mellitus (T2DM). They were not taking any medicines that could alter the lipid levels of serum. Before the beginning of the study, all participants had provided written informed consent. The study protocol was approved by the Ethics Committee of the First Affiliated Hospital, Guangxi Medical University (No. Lunshen-2014 KY-Guoji-001, Mar. 7, 2014).

\section{Epidemiological analysis}

Universally standardized methods and protocols were used to conduct the epidemiological survey [23]. By using a standard set of questionnaires, details regarding lifestyle as well as demographic factors were collected. Alcohol consumption ( 0 (non-drinker), $<25 \mathrm{~g} /$ day and $\geq 25 \mathrm{~g} /$ day) and smoking status ( 0 (non-smoker), $<20$ cigarettes/ day and $\geq 20$ cigarettes/day) were divided into three different subgroups. Current smoking was defined as more than one cigarette per day. The subjects who reported having smoked $\geq 100$ cigarettes during their lifetime were classified as current smokers if they currently smoked and former smokers if they did not [21,22]. As per the methods in previously published studies, the weight, height, body mass index (BMI, $\mathrm{kg} / \mathrm{m}^{2}$ ), blood pressure, and waist circumference were measured [24]. 


\section{Biochemical assays}

A fasting venous blood sample $(5 \mathrm{~mL})$ was collected from each participant. A part of the sample $(2 \mathrm{~mL})$ was collected into glass tubes to measure serum lipid levels. The remaining $3 \mathrm{~mL}$ of the sample was collected in the tubes containing anticoagulants $(13.20 \mathrm{~g} / \mathrm{L}$ tri-sodium citrate, $4.80 \mathrm{~g} / \mathrm{L}$ citric acid, and $14.70 \mathrm{~g} / \mathrm{L}$ glucose) and was utilized to extract deoxyribonucleic acid (DNA). Measurements of serum TG, TC, LDL-C, and HDL-C levels in the samples were performed by enzymatic methods with commercially available kits (RANDOX Laboratories Ltd., Ardmore, Diamond Road, Crumlin Co. Antrim, United Kingdom, BT29 4QY; Daiichi Pure Chemicals Co., Ltd., Tokyo, Japan). Serum ApoA1 and ApoB levels were detected by the immunoturbidimetric immunoassay using a commercial kit (APO CAL; cat. no. LP3023; Randox Laboratories, Ltd) [25]. Fasting blood glucose was determined with a glucose meter (Accu-Chek; F. Hoffman-La Roche AG, Basel, Switzerland). The values of serum lipid levels were tested by using an autoanalyzer (Type 7170A; Hitachi Ltd., Tokyo, Japan) in the Clinical Science Experiment Center of the First Affiliated Hospital, Guangxi Medical University [26, 27].

\section{Amplification of DNA and genotyping}

The phenol-chloroform method was used to isolate genomic DNA from the peripheral blood leucocytes of the blood samples $[28,29]$. The extracted DNA samples were stored at $4{ }^{\circ} \mathrm{C}$ till further use. PCR-RFLP was used to determine the SLC44A4 rs577272 and NOTCH4 rs3134931 SNP genotypes. The primer sequences of the SLC44A4 rs577272 and NOTCH4 rs3134931 SNPs as follows: forward $5^{\prime}$-ACTGTAGGTGCTCACTGGAT- ${ }^{\prime}$ and reversed $5^{\prime}$-GATTCGTATTGCCATCGCCC-3'; forward $5^{\prime}$-AGAAGAGGAAAGGTGGAGGC- ${ }^{\prime}$ and reversed 5'-AAGCTGGGTGTCAATGGAGA-3' (Sangon, Shanghai, People's Republic of China); respectively. The PCR reaction mixture (final volume: $25 \mu \mathrm{L}$ ) contained $2.0 \mu \mathrm{L}$ of genomic DNA, $1.0 \mu \mathrm{L}$ of each primer $(10 \mu \mathrm{mol} / \mathrm{L})$, $12.5 \mu \mathrm{L}$ of $2 \times$ Taq PCR Master Mix (constituent: $0.1 \mathrm{U}$ Taq polymerase $/ \mu \mathrm{L}, 500 \mu \mathrm{M}$ dNTP each and PCR buffer, Tiangen, Beijing, People's Republic of China.), and $8.5 \mu \mathrm{L}$ of DNase/RNase-free $\mathrm{ddH}_{2} \mathrm{O}$. The cycle details for the reaction are as follows: $95^{\circ} \mathrm{C}$ for $5 \mathrm{~min}, 95{ }^{\circ} \mathrm{C}$ for $30 \mathrm{~s}$ for denaturing, $59^{\circ} \mathrm{C}$ for $30 \mathrm{~s}$ for annealing, and elongation for $35 \mathrm{~s}$ at $72{ }^{\circ} \mathrm{C}$ for 35 cycles. The final extension of $72{ }^{\circ} \mathrm{C}$ for $7 \mathrm{~min}$ was used to finish amplification. Electrophoresis was done by using $2.0 \%$ agarose gels to run PCR products and bands were visualized by using ultraviolet light (Universal Hood II; Bio-Rad Laboratories, Inc., Hercules, CA, USA), and the PCR products located in 522- and 490-bp bands represent the target genes.
The restriction enzyme reaction system includes $5.0 \mu \mathrm{L}$ amplified DNA, $8.8 \mu \mathrm{L}$ nuclease-free water, $1.0 \mu \mathrm{L}$ of $10 \times$ buffer solution and $0.2 \mu \mathrm{L} R s a \mathrm{I}$ restriction enzyme in a total volume of $15 \mu \mathrm{L}$ digested at $37{ }^{\circ} \mathrm{C}$ overnight. Restriction enzyme was used to digest the amplified DNA. Next, the genotypes were recognized by running an electrophoresis with 2.0\% agarose gel and were visualized under ultraviolet light (Universal Hood II; Bio-Rad Laboratories, Inc., Hercules, CA, USA). An experienced reader who was unaware of the epidemiological data and lipid levels scored genotypes. Different bands of enzyme-digested products represent different genotypes of SLC44A4 rs577272 polymorphism (AA genotype, 522bp; GA genotype, 522-, 448- and 74-bp; GG genotype, 448- and 74-bp); NOTCH4 rs3134931 polymorphism (AA genotype, 490 bp; AG genotype 490-, 306- and 184bp; GG genotype, 306- and 184-bp). Six samples detected by PCR-RFLP were also established by direct sequencing with an ABI Prism 3100 (Applied Biosystems, Shanghai Sangon Biological Engineering Technology \& Services Co. Ltd., China).

\section{Analytical measures}

Serum ApoB (0.80-1.05 g/L), TG (0.56-1.70 mmol/L), LDL-C (2.70-3.10 $\mathrm{mmol} / \mathrm{L})$, TC $(3.10-5.17 \mathrm{mmol} / \mathrm{L})$, HDL-C (1.16-1.42 mmol/L), ApoA1 (1.20-1.60 g/L) levels and the ApoA1/ApoB ratio (1.00-2.50) were defined as normal values at our Clinical Science Experiment Center. The participants with TC $>5.17 \mathrm{mmol} / \mathrm{L}$ and/ or TG $>1.70 \mathrm{mmol} / \mathrm{L}$ were defined as HLP [30]. The diagnostic criteria of hypertension [31] and diabetes [32], overweight, normal weight, obesity [33] were also referred to previous studies.

\section{Statistical analyses}

All data were evaluated by using SPSS (Version 22.0). The values of quantitative variables were presented as mean \pm SD. Only serum TG levels were reported as medians and interquartile ranges. Direct counting was used to determine allele frequency. The standard goodness-of-fit test was utilized to verify the Hardy-Weinberg equilibrium (HWE). Chi-square test was used to assess the differences in the genotype distribution of selected 2 SNPs, the proportion of smokers and alcohol consumption between the two populations. The difference in general characteristics between Han and Maonan was analyzed by the independent-samples $t$ test. Covariance analysis (ANCOVA) was used to test the relationship between blood lipid parameters and genotypes, and $P<0.025$ (equivalent to $P<0.05$ after adjusting for 2 SNPs independent tests by Bonferroni correction) was considered significantly statistical significance. The correlation between haplotypes/genotypes and the occurrence of 
HLP was detected by unconditional logistic regression analysis. Age, gender, BMI, alcohol consumption, cigarette smoking, and blood pressure were adapted for the statistical analysis. In order to estimate the link between the genotypes and some environmental elements with blood lipid levels in males and females of Han and Maonan populations, multivariable linear regression analysis with stepwise modeling was used. $P$ value of $<0.05$ was considered as statistically significant. Interactive heat map with several parameters related to blood lipid levels was drawn by R software (version 3.3.0) [34].

\section{Results}

\section{General and biochemical characteristics}

As mentioned in Table 1, the ApoA1/ApoB ratio, HDL-C and ApoA1 levels, were greater in Han than in Maonan nationalities $(P<0.05)$. The levels of serum TG, TC, LDL-C and ApoB, systolic and diastolic blood pressure, pulse pressure, the proportion of smokers and alcohol consumption were lesser in the Han than in the Maonan nationalities $(P<0.05-0.001)$. There was no obvious difference in age distribution, gender, height, BMI, weight, waist circumference and glucose between Han and Maonan nationalities. Subgroup analysis also found that the levels of ApoB, TC, weight, glucose, BMI, waist circumference, TG, systolic blood pressure, LDL-C, the proportion of smokers, diastolic blood pressure, alcohol consumption and pulse pressure were higher in HLP than in normal subjects in both Han and Maonan groups; the levels of ApoA1, HDL-C and the ApoA1/ApoB ratio were less in HLP than in normal subjects in both Han and Maonan groups; there was no any obvious difference in following factors such as gender, height, and age distribution in HLP than in normal subjects in both Han and Maonan groups.

\section{Results of electrophoresis and genotyping}

Results from PCR and electrophoresis showed that each sample had the presence of 522-bp (Fig. 1a1) nucleotide sequences. The AA (522-bp), AG (522-, 448- and 74-bp) and GG (448- and 74-bp) genotypes of rs577272 SNP were shown in Fig. 1a2, respectively. The PCR product of the rs3134931 SNP was 490-bp nucleotide sequences (Fig. 1b1). The GG (490-bp), AG (490-, 306- and 184bp) and AA (306- and 184-bp) genotypes were shown in Fig. 1b2, respectively. In addition, the genotypes of rs577272 and rs3134931 SNPs detected by PCR-RFLP were also verified by direct sequencing (Fig. 2).

\section{Genotypic and allelic frequencies and the connection with serum lipid levels and the risk of HLP}

The genotypic scattering of the SLC44A4 rs577272 and NOTCH4 rs3134931 SNPs in both Han and Maonan populations conformed to HWE $(P>0.05)$. As shown in Table 2, the genotype frequencies of SLC44A4 rs577272 and NOTCH4 rs3134931 SNPs were different between Han and Maonan populations $(P<0.05)$; respectively. As shown in Table 3, the genotypes of the rs577272 SNP were associated with the risk of HLP in different genetic models: co-dominant model: $\mathrm{GA}$ versus $\mathrm{AA}(\mathrm{OR}=1.69$, 95\% $\mathrm{CI}=1.27-2.24, \quad P=0.0011)$; dominant model: $\mathrm{GA} / \mathrm{GG}$ versus $\mathrm{AA}(\mathrm{OR}=1.65,95 \% \mathrm{CI}=1.25-2.17$, $P<0.0001)$; overdominant model: AA/GG versus GA $(\mathrm{OR}=1.60,95 \% \mathrm{CI}=1.23-2.08, P<0.0001)$ and log-additive model: $\mathrm{G}$ versus $\mathrm{A}(\mathrm{OR}=1.36,95 \% \mathrm{CI}=1.09-1.71$, $P=0.0067)$ in Maonan ethnic group. The genotypes of the rs3134931 SNP were associated with the risk of HLP in different genetic models: co-dominant model: AG versus $\mathrm{GG}(\mathrm{OR}=1.32,95 \% \mathrm{CI}=0.98-1.78, P<0.0001)$; dominant model: AG/AA versus $G G(\mathrm{OR}=1.58,95 \%$ $\mathrm{CI}=1.19-2.09, \quad P=0.0014)$; recessive model: $\mathrm{GG} / \mathrm{AG}$ versus $\mathrm{AA}(\mathrm{OR}=1.94,95 \% \mathrm{CI}=1.46-2.57, P<0.0001)$ and log-additive model: A versus $\mathrm{G}(\mathrm{OR}=1.53,95 \%$ $\mathrm{CI}=1.29-1.82, P<0.0001)$ in Han ethnic group and co-dominant model: AG versus $\mathrm{GG}(\mathrm{OR}=1.46,95 \%$ $\mathrm{CI}=1.10-1.95, P=0.0016)$; dominant model: AG/AA versus $\mathrm{GG}(\mathrm{OR}=1.57,95 \% \mathrm{CI}=1.21-2.04, P<0.0001)$; recessive model: $\mathrm{GG} / \mathrm{AG}$ versus $\mathrm{AA}(\mathrm{OR}=1.45,95 \%$ $\mathrm{CI}=1.08-1.96, P<0.014)$ and log-additive model: A versus $\mathrm{G}(\mathrm{OR}=1.35,95 \% \mathrm{CI}=1.14-1.59, \quad P<0.0001)$ in Maonan ethnic group. As shown in Table 4, The SLC44A4 rs577272 SNP was associated with TC and HDL-C in Maonan group, the NOTCH4 rs3134931 SNP was associated with TG in Han; TG and LDL-C in Maonan group $(P<0.025-0.001)$. Stratified analysis according to gender showed that the SLC44A4 rs577272 SNP was associated with TC in Maonan males; TC and HDL-C in Han and Maonan females; TC in Maonan males, meanwhile, the NOTCH4 rs3134931 SNP was associated with TG and HDL-C in Han males; TG in Han females; TG and LDL-C in Maonan males; TG, HDL-C and LDL-C in Maonan females $(P<0.025-0.001)$.

\section{Haplotype-based association with serum lipid levels and HLP}

Figure 3 indicates that there was strong pairwise linkage disequilibrium (LD) among the detected loci in both Han (A) and Maonan (B) groups. As shown in the Table 5, the dominant haplotype was the rs577272G-rs3134931A ( $>50 \%$ of the samples). The haplotype of the rs577272Grs3134931A was related to an increased morbidity of HLP in the both Han and Maonan groups, At the same time, Fig. 4 indicates that the haplotype of rs577272Grs3134931A was associated with TG and HDL-C levels in Han; TC, TG and HDL-C levels in Maonan ethnic groups $(P<0.05-0.001$, respectively). In addition, multivariate 
Table 1 Comparison of demographic, lifestyle characteristics and serum lipid levels between the Han and Maonan populations

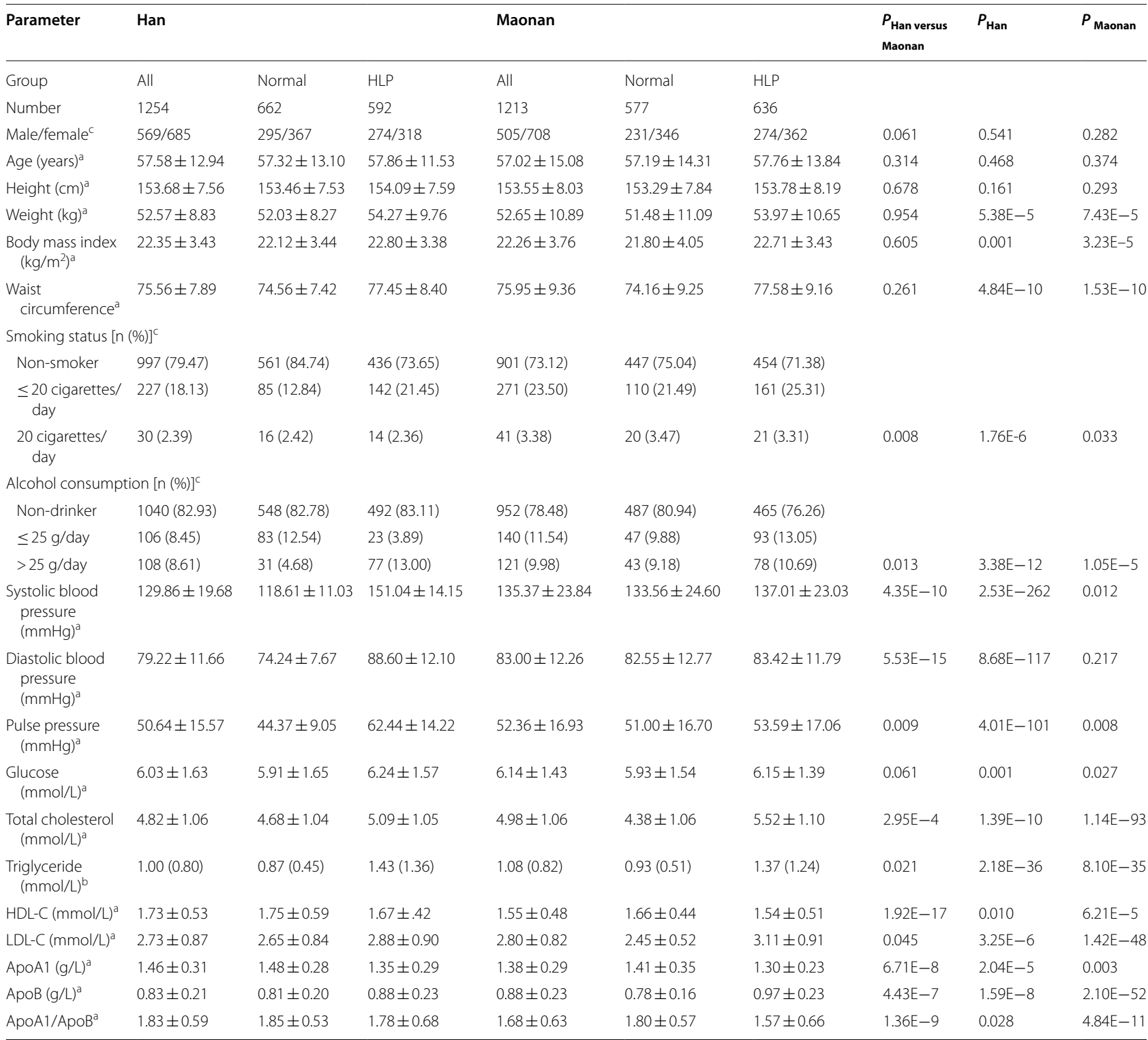

$H D L-C$ high-density lipoprotein cholesterol, $L D L-C$ low-density lipoprotein cholesterol, Apo apolipoprotein, HLP hyperlipidaemia. The value of triglyceride was presented as median (interquartile range) for not a normal distribution

a Mean $\pm S D$ determined by $t$ test

b Median (interquartile range) tested by the Wilcoxon-Mann-Whitney test

c The rate or constituent ratio between the different groups was analyzed by the chi-square test

logistic analysis showed that the rs577272G-rs3134931A haplotype was positively correlated with the incidence of HLP in Han and Maonan according to stratified risk factors (gender, BMI, smoking, diabetes and blood pressure; Table 6).

\section{Relationship among lipid parameters and alleles/} genotypes

Table 7 indicates that the association between serum lipid parameters and the alleles and/or genotypes of two selected SNPs in Han and Maonan groups. The results showed that the alleles of rs 577272 were 

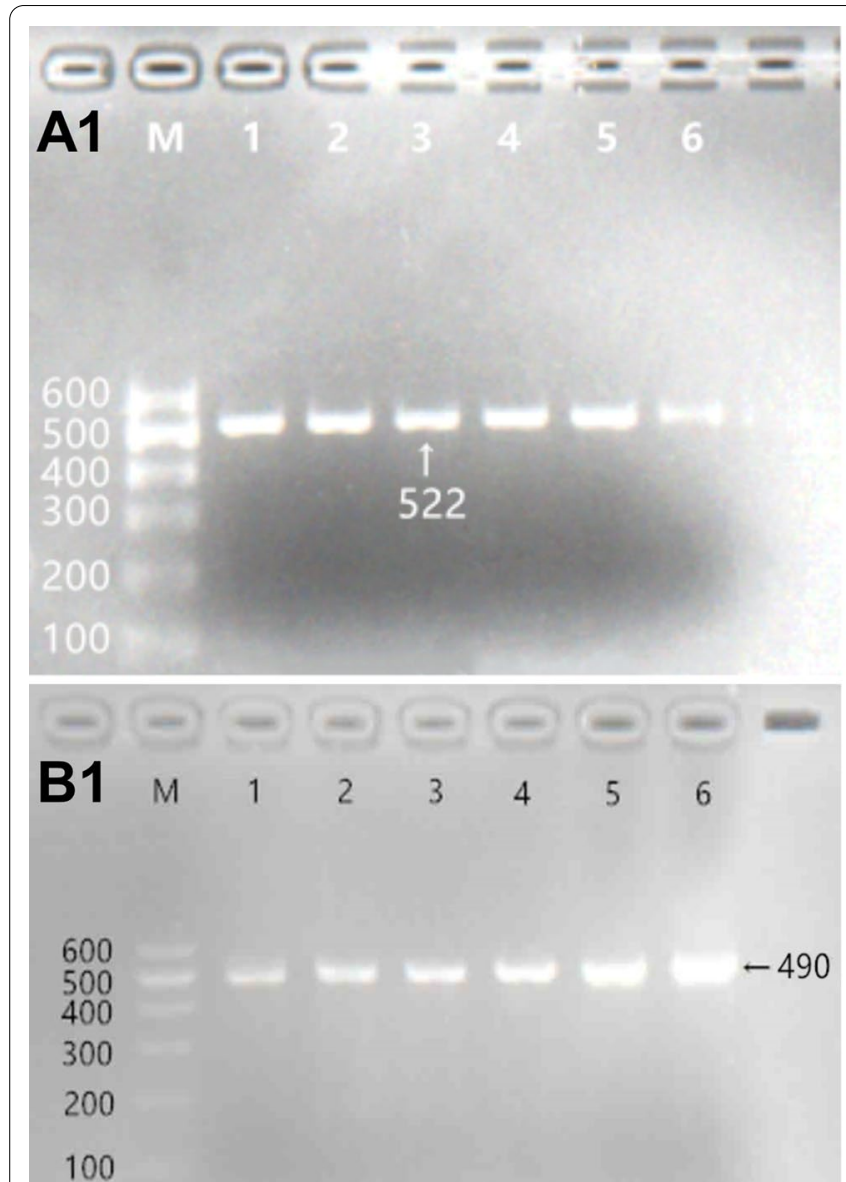

100

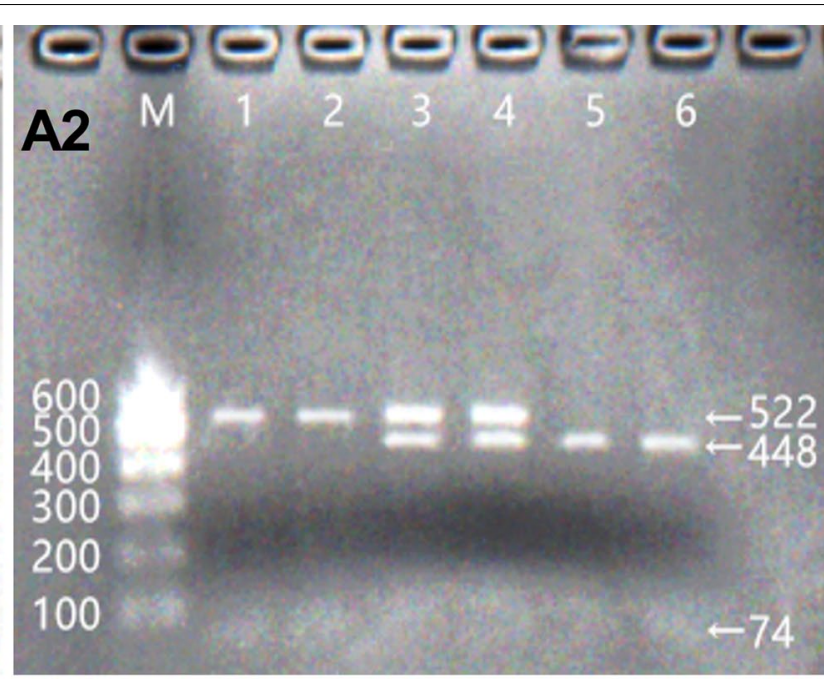

$\begin{array}{llllllll}\text { B2 } & \text { M } & 1 & 2 & 3 & 4 & 5 & 6\end{array}$

600

500

400

300

200

100

Fig. 1 Agarose gel electrophoresis (2\%) of PCR products and genotyping of the SLC44A4 rs577272 and NOTCH4 rs3134931 SNPs. a1, a2 (rs577272): Lane $\mathrm{M}$ is the 100 bp marker ladder; Lanes 1-6 are samples, the 522 bp is the target genes. lanes 1 and 2, AA genotype (522 bp); lanes 3 and 4, AG genotype (522-, 448- and 74-bp); and lanes 5 and 6, GG genotype (448- and 74-bp). b1, b2 (rs3134931): Lane M is the 100 bp marker ladder; Lanes 1-6 are samples, the 490 bp is the target genes. lanes 1 and 2, GG genotype (490 bp); lanes 3 and 4, AG genotype (490-, 306- and 184-bp); and lanes 5 and 6, AA genotype (306- and 184-bp)

associated with TC and HDL-C in Han and Maonan ethnic groups; and the genotypes of rs577272 were associated with TC and HDL-C in Maonan ethnic group; the alleles of rs3134931 were associated with TC and HDL-C in Han enthic group and TG, HDL-C and LDL-C in Maonan ethnic group; the genotypes of rs3134931 were associated with TG in Han ethnic group and TG and LDL-C in Maonan ethnic group $(P<0.005-0.001)$; respectively.

Correlated environment factors for serum lipid parameters As shown in Tables 8 and 9, multivariable linear regression analysis showed that several environmental factors such as gender, age, glucose levels, waist circumference, BMI, systolic and diastolic blood pressure, pulse pressure, smoking and drinking were associated with serum lipid parameters in both ethnic groups or in males and females $(P<0.05-0.001$ for all $)$.

\section{Relative factors for serum lipid parameters}

As shown in Fig. 5, Pearson correlation analysis suggested that the SLC44A4 rs577272 and NOTCH4 rs3134931 SNPs were connected with serum lipid levels. Several environmental factors such as weight, gender, height, age, waist circumference, alcohol consumption, cigarette smoking, BMI and blood pressure levels were also correlated with serum lipid parameters in both ethnic groups. 


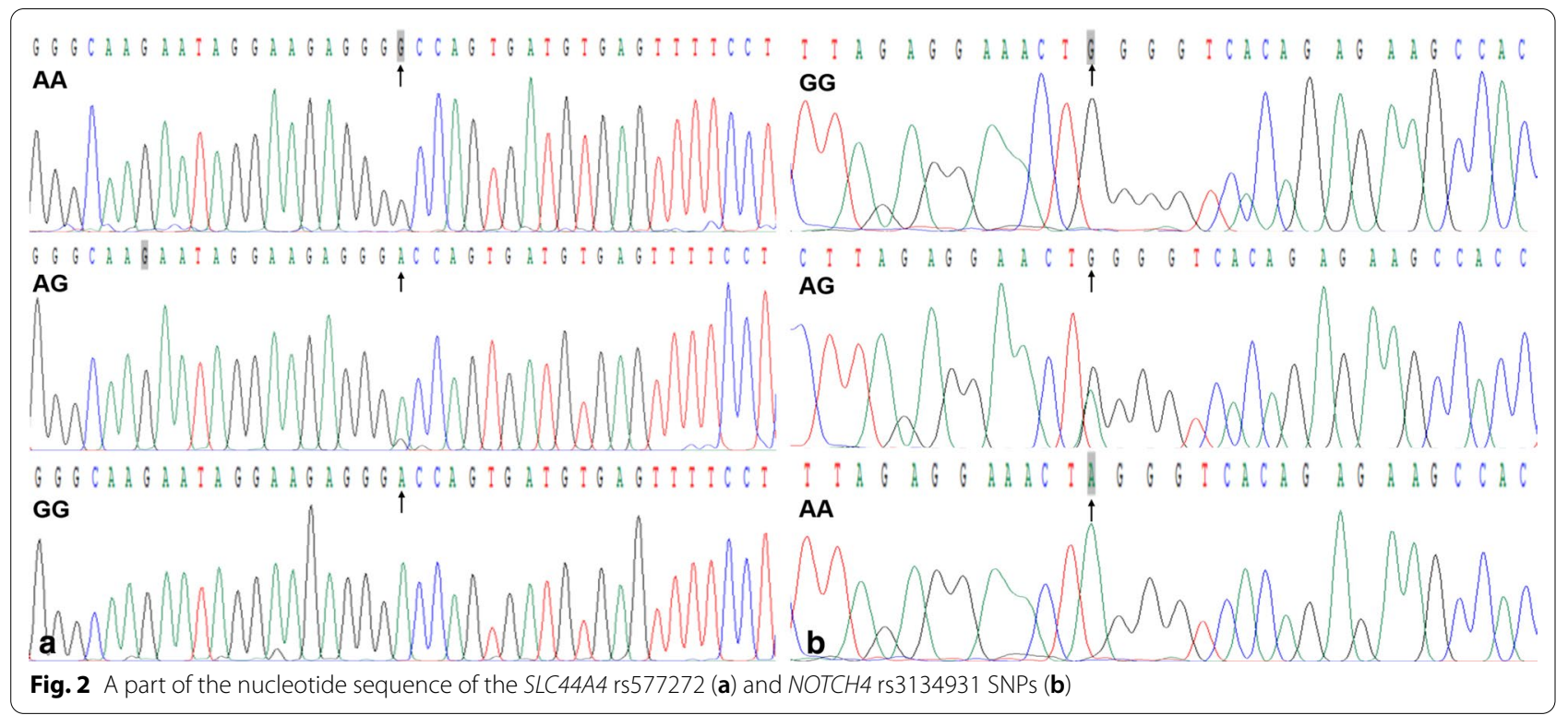

Table 2 Genotypic and allelic frequencies of the two SNPs in the Han and Maonan ethnic groups [n (\%)]

\begin{tabular}{|c|c|c|c|c|c|c|c|c|c|c|}
\hline \multirow[t]{2}{*}{ SNP } & \multirow[t]{2}{*}{ Genotype } & \multicolumn{3}{|l|}{ Han } & \multicolumn{3}{|l|}{ Maonan } & \multirow[t]{2}{*}{$P_{\text {Han versus Maonan }}$} & \multirow[t]{2}{*}{$P_{\text {Han }}$} & \multirow[t]{2}{*}{$P_{\text {Maoan }}$} \\
\hline & & $\begin{array}{l}\text { All } \\
(n=1254)\end{array}$ & $\begin{array}{l}\text { Normal } \\
(n=662)\end{array}$ & $\begin{array}{l}\text { HLP } \\
(n=592)\end{array}$ & $\begin{array}{l}\text { All } \\
(n=1213)\end{array}$ & $\begin{array}{l}\text { Normal } \\
(n=577)\end{array}$ & $\begin{array}{l}\text { HLP } \\
(n=636)\end{array}$ & & & \\
\hline \multirow[t]{6}{*}{$\begin{array}{l}\text { SLC44A4 rs577272 } \\
A>G\end{array}$} & $\mathrm{~A} / \mathrm{A}$ & $\begin{array}{l}394 \\
(31)\end{array}$ & $\begin{array}{l}215 \\
(32)\end{array}$ & $\begin{array}{l}179 \\
(30)\end{array}$ & $\begin{array}{l}309 \\
(25)\end{array}$ & $\begin{array}{l}182 \\
(32)\end{array}$ & $\begin{array}{l}127 \\
(20)\end{array}$ & & & \\
\hline & $A / G$ & $\begin{array}{l}638 \\
(51)\end{array}$ & $\begin{array}{l}331 \\
(50)\end{array}$ & $\begin{array}{l}307 \\
(52)\end{array}$ & $\begin{array}{l}602 \\
(50)\end{array}$ & $\begin{array}{l}270 \\
(47)\end{array}$ & $\begin{array}{l}332 \\
(52)\end{array}$ & & & \\
\hline & $\mathrm{G} / \mathrm{G}$ & $\begin{array}{l}222 \\
(18)\end{array}$ & $\begin{array}{l}116 \\
(18)\end{array}$ & $\begin{array}{l}106 \\
(18)\end{array}$ & $\begin{array}{l}302 \\
(25)\end{array}$ & $\begin{array}{l}125 \\
(22)\end{array}$ & $\begin{array}{l}177 \\
(28)\end{array}$ & $1.09 E-5$ & 0.692 & $1.43 \mathrm{E}-5$ \\
\hline & G & $\begin{array}{l}1426 \\
(57)\end{array}$ & $\begin{array}{l}761 \\
(57)\end{array}$ & $\begin{array}{l}665 \\
(56)\end{array}$ & $\begin{array}{l}1220 \\
(50)\end{array}$ & $\begin{array}{l}634 \\
(55)\end{array}$ & $\begin{array}{l}586 \\
(46)\end{array}$ & & & \\
\hline & A & $\begin{array}{l}1082 \\
(43)\end{array}$ & $\begin{array}{l}563 \\
(43)\end{array}$ & $\begin{array}{l}519 \\
(44)\end{array}$ & $\begin{array}{l}1206 \\
(50)\end{array}$ & $\begin{array}{l}520 \\
(45)\end{array}$ & $\begin{array}{l}686 \\
(54)\end{array}$ & $3.73 E-6$ & 0.508 & $1.28 \mathrm{E}-5$ \\
\hline & $P_{\text {HWE }}$ & 0.21 & 0.58 & 0.21 & 0.82 & 0.21 & 0.23 & & & \\
\hline \multirow[t]{6}{*}{$\begin{array}{l}\text { NOTCH4 rs3134931 } \\
\text { G>A }\end{array}$} & $\mathrm{G} / \mathrm{G}$ & $\begin{array}{l}315 \\
(25)\end{array}$ & $\begin{array}{l}183 \\
(28)\end{array}$ & $\begin{array}{l}132 \\
(22)\end{array}$ & $\begin{array}{l}352 \\
(29)\end{array}$ & $\begin{array}{l}200 \\
(35)\end{array}$ & $\begin{array}{l}152 \\
(24)\end{array}$ & & & \\
\hline & $A / G$ & $\begin{array}{l}625 \\
(50)\end{array}$ & $\begin{array}{l}344 \\
(52)\end{array}$ & $\begin{array}{l}281 \\
(47)\end{array}$ & $\begin{array}{l}595 \\
(49)\end{array}$ & $\begin{array}{l}267 \\
(46)\end{array}$ & $\begin{array}{l}328 \\
(52)\end{array}$ & & & \\
\hline & $\mathrm{AA}$ & $\begin{array}{l}314 \\
(25)\end{array}$ & $\begin{array}{l}135 \\
(20)\end{array}$ & $\begin{array}{l}179 \\
(30)\end{array}$ & $\begin{array}{l}266 \\
(22)\end{array}$ & $\begin{array}{l}100 \\
(19)\end{array}$ & $\begin{array}{l}156 \\
(25)\end{array}$ & 0.048 & $2.12 E-4$ & $2.54 \mathrm{E}-5$ \\
\hline & G & $\begin{array}{l}1255 \\
(50)\end{array}$ & $\begin{array}{l}710 \\
(54)\end{array}$ & $\begin{array}{l}545 \\
(46)\end{array}$ & $\begin{array}{l}1299 \\
(54)\end{array}$ & $\begin{array}{l}667 \\
(58)\end{array}$ & $\begin{array}{l}632 \\
(50)\end{array}$ & & & \\
\hline & A & $\begin{array}{l}1253 \\
(50)\end{array}$ & $\begin{array}{l}614 \\
(46)\end{array}$ & $\begin{array}{l}639 \\
(54)\end{array}$ & $\begin{array}{l}1127 \\
(46)\end{array}$ & $\begin{array}{l}487 \\
(42)\end{array}$ & $\begin{array}{l}640 \\
(50)\end{array}$ & 0.014 & $1.46 \mathrm{E}-4$ & $6.29 \mathrm{E}-5$ \\
\hline & $P_{\text {HWE }}$ & 0.27 & 0.49 & 0.23 & 0.64 & 0.23 & 0.48 & & & \\
\hline
\end{tabular}

$P$ value defined as Chi-square test probability

SLC44A4 the synaptotagmin like 3 gene, NOTCH4 the solute carrier family 22 member 3 gene, HLP hyperlipidaemia, HWE Hardy-Weinberg equilibrium

\section{Discussion}

The main findings of the current research included the following aspects: (1) It revealed that the genotype frequencies of SLC44A4 rs577272 and NOTCH4 rs3134931
SNPs were significantly different between Han and Maonan populations. (2) The SLC44A4 rs577272 SNP was associated with TC and HDL-C in Maonan ethnic group, the NOTCH4 rs3134931 SNP was associated with TG 
Table 3 Risk for gene models in each SNP between the normal and HLPpopulations

\begin{tabular}{|c|c|c|c|c|c|c|c|}
\hline \multirow[t]{2}{*}{ SNP } & \multirow[t]{2}{*}{ Model } & \multicolumn{2}{|l|}{ Genotype } & \multicolumn{2}{|l|}{ Han } & \multicolumn{2}{|l|}{ Maonan } \\
\hline & & Reference & Effect & OR $(95 \% \mathrm{Cl})$ & $P$ & OR $(95 \% \mathrm{Cl})$ & $P$ \\
\hline \multirow[t]{6}{*}{ rs577272 A>G } & Co-dominant & $A / A$ & $\mathrm{G} / \mathrm{A}$ & $0.90(0.68-1.18)$ & 0.36 & $1.69(1.27-2.24)$ & 0.0011 \\
\hline & & & $\mathrm{G} / \mathrm{G}$ & $0.77(0.54-1.10)$ & & $1.31(0.77-2.22)$ & \\
\hline & Dominant & $A / A$ & $\mathrm{G} / \mathrm{A}+\mathrm{G} / \mathrm{G}$ & $0.86(0.66-1.12)$ & 0.27 & $1.65(1.25-2.17)$ & $4 \mathrm{E}-04$ \\
\hline & Recessive & $\mathrm{A} / \mathrm{A}+\mathrm{G} / \mathrm{A}$ & $\mathrm{G} / \mathrm{G}$ & $0.82(0.60-1.13)$ & 0.23 & $0.91(0.56-1.48)$ & 0.7 \\
\hline & Overdominant & $\mathrm{A} / \mathrm{A}+\mathrm{G} / \mathrm{G}$ & $\mathrm{G} / \mathrm{A}$ & $0.99(0.77-1.26)$ & 0.92 & $1.60(1.23-2.08)$ & $4 \mathrm{E}-04$ \\
\hline & Log-additive & & & $0.88(0.74-1.05)$ & 0.16 & $1.36(1.09-1.71)$ & 0.0067 \\
\hline \multirow[t]{6}{*}{ rs3134931 G>A } & Co-dominant & $\mathrm{G} / \mathrm{G}$ & $\mathrm{A} / \mathrm{G}$ & $1.32(0.98-1.78)$ & $<0.0001$ & $1.46(1.10-1.95)$ & 0.0016 \\
\hline & & & $A / A$ & $2.33(1.65-3.29)$ & & $1.79(1.27-2.50)$ & \\
\hline & Dominant & $\mathrm{G} / \mathrm{G}$ & $\mathrm{A} / \mathrm{G}+\mathrm{A} / \mathrm{A}$ & $1.58(1.19-2.09)$ & 0.0014 & $1.57(1.21-2.04)$ & $7 E-04$ \\
\hline & Recessive & $\mathrm{G} / \mathrm{G}+\mathrm{A} / \mathrm{G}$ & $A / A$ & $1.94(1.46-2.57)$ & $<0.0001$ & $1.45(1.08-1.96)$ & 0.014 \\
\hline & Overdominant & $\mathrm{G} / \mathrm{G}+\mathrm{A} / \mathrm{A}$ & $\mathrm{A} / \mathrm{G}$ & $0.86(0.68-1.10)$ & 0.24 & $1.17(0.91-1.50)$ & 0.24 \\
\hline & Log-additive & & & $1.53(1.29-1.82)$ & $<0.0001$ & $1.35(1.14-1.59)$ & $4 \mathrm{E}-04$ \\
\hline
\end{tabular}

$P$ value defined as Logistic test probability

$O R$ odds ratio, $\mathrm{Cl}$ confidence interval

in Han, TG and LDL-C in Maonan ethnic groups. (3) Stratified analysis according to gender showed that the SLC44A4 rs577272 SNP was associated with TC and HDL-C in Han and Maonan females; TC in Maonan males, meanwhile, the NOTCH4 rs3134931 SNP was associated with TG and HDL-C in Han males; TG in Han females; TG and LDL-C in Maonan males; and TG, HDL-C and LDL-C in Maonan females.

A lot of studies have showed that HLP as a severe risk factor for CHD, may be due to the combined effects of various elements, just as the age, gender, lifestyle, genetic background, environmental factors and their interactions $[35,36]$. HLP acts as a highly hereditary disease, about $40-60 \%$ of the variation in serum lipid profile determined by heredity [37]. The mutation rate of SLC44A4 rs577272 and NOTCH4 rs3134931 SNPs was diverse amongst various origins. As per the HapMap data, the occurrence of rs577272G allele was $42.7 \%$ in Chinese, $48.3 \%$ in American, $33.5 \%$ in Italian, $35.0 \%$ in Kenyan and $34.3 \%$ in Japanese and $45.6 \%$ in European population. At the same time, the occurrence of rs3134931A allele was $47.6 \%$ in Chinese, $43.6 \%$ in Japanese, $55.3 \%$ in Yoruba, $67.6 \%$ in Italian, $53.5 \%$ in Kenyan, $57 \%$ in Mexican, and $69.5 \%$ in European population. However, the genotypic and allelic frequencies of the SLC44A4 rs577272 and NOTCH4 rs3134931 SNPs have not been reported previously in Maonan group. In this study, we firstly reported that the frequencies of rs577272G allele and AG, GG genotypes were 50\%, 50\% and 25\%; rs3134931A allele and AG, AA genotypes were $46 \%, 49 \%$ and $22 \%$; respectively. It means the frequencies of the rare homozygous genotype and minor allele of two selected SNPs were different between European and Asian. The above results indicated that the frequencies of minor allele or rare homozygous genotype of selected 2 SNPs would be shared a racial/ethnic-specificity. We speculated that the differences in blood lipid levels between the two ethnic groups might partly be attributed to the differences in the genotype frequencies of the two SNPs.

Previous studies suggested that plasma concentrations of TG, TC, LDL-C, HDL-C were the most important risk factors for $\mathrm{CHD}$ and targets for therapeutic intervention [38]. At the same time, CRP was a marker of chronic inflammation that was closely associated with CHD [39], and some clinical studies showed that a synergistic effect of statin therapy on the reducing of CRP and LDL-C, which suggested that lipids and inflammation may share some biological pathways [40, 41]. Previous studies have also identified that the SLC44A4 rs577272 SNP is associated with serum TC and CRP levels. In addition, the NOTCH4 rs3134931 SNP was highly associated with circulating serum or plasma MPO levels, which were responsible for the incidence as well as development of the CHD and ischemic stroke [15, 42]. At the same time, high circulating levels of MPO in serum, plasma, or white blood cells could be used as a predictor of major cardiac adverse events in healthy people and in patients with CHD or heart failure [43-46]. Furthermore, MPO has been demonstrated to be linked to some traditional risk factors that associated with $\mathrm{CHD}$, just as sex, age, BMI, blood pressure, glucose, smoking and drinking habits [47-49]. MPO-derived oxidants were involved in the development of atherogenic low-density lipoprotein particles, the formation of dysfunctional HDL particles, catalytic consumption of nitric oxide, inflammatory injury of the vascular endothelium, and progression 
Table 4 Comparison of the genotypes and serum lipid levels in the Han and Maonan populations

\begin{tabular}{|c|c|c|c|c|c|c|c|c|}
\hline Genotype & $\mathrm{n}$ & $\mathrm{TC}$ (mmol/L) & TG (mmol/L) & $\mathrm{HDL}-\mathrm{C}(\mathrm{mmol} / \mathrm{L})$ & LDL-C (mmol/L) & ApoA1 (g/L) & ApoB (g/L) & ApoA1/ApoB \\
\hline \multicolumn{9}{|c|}{ SLC44A4 rs577272 } \\
\hline \multicolumn{9}{|l|}{ Han } \\
\hline AA & 394 & $4.75 \pm 1.02$ & $0.98(0.76)$ & $1.71 \pm 0.45$ & $2.70 \pm 0.93$ & $1.43 \pm 0.27$ & $0.84 \pm 0.24$ & $1.81 \pm 0.50$ \\
\hline$A G+G G$ & 860 & $4.86 \pm 0.98$ & $1.06(0.83)$ & $1.73 \pm 0.57$ & $2.74 \pm 0.84$ & $1.44 \pm 0.29$ & $0.83 \pm 0.20$ & $1.83 \pm 0.62$ \\
\hline F & & 5.650 & -0.601 & 1.527 & 2.674 & 1.320 & 1.482 & 2.873 \\
\hline$P$ & & 0.077 & 0.448 & 0.539 & 0.449 & 0.779 & 0.728 & 0.424 \\
\hline \multicolumn{9}{|l|}{ Han/Male } \\
\hline AA & 117 & $4.95 \pm 0.99$ & $0.99(0.83)$ & $1.64 \pm 0.43$ & $2.78 \pm 0.85$ & $1.38 \pm 0.22$ & $0.80 \pm 0.23$ & $1.82 \pm 0.51$ \\
\hline$A G+G G$ & 442 & $5.15 \pm 1.06$ & $1.11(0.78)$ & $1.75 \pm 0.53$ & $2.92 \pm 0.82$ & $1.40 \pm 0.26$ & $0.80 \pm 0.20$ & $1.84 \pm 0.61$ \\
\hline$F$ & & 6.946 & -2.104 & 3.295 & 4.049 & 1.618 & 0.936 & 1.347 \\
\hline$P$ & & 0.047 & 0.035 & 0.311 & 0.123 & 0.632 & 0.955 & 0.768 \\
\hline \multicolumn{9}{|l|}{ Han/Female } \\
\hline AA & 277 & $4.56 \pm 1.15$ & $0.92(0.68)$ & $1.84 \pm 0.45$ & $2.61 \pm 0.96$ & $1.53 \pm 0.29$ & $0.91 \pm 0.26$ & $1.83 \pm 0.50$ \\
\hline $\mathrm{AG}+\mathrm{GG}$ & 418 & $4.78 \pm 1.01$ & $1.04(0.82)$ & $1.69 \pm 0.61$ & $2.70 \pm 0.83$ & $1.49 \pm 0.32$ & $0.90 \pm 0.28$ & $1.80 \pm 0.63$ \\
\hline$F$ & & 7.633 & -1.991 & 8.117 & 3.884 & 7.189 & 0.980 & 3.669 \\
\hline P & & 0.018 & 0.046 & 0.011 & 0.200 & 0.032 & 0.856 & 0.231 \\
\hline \multicolumn{9}{|l|}{ Maonan } \\
\hline AA & 309 & $4.80 \pm 1.12$ & 1.09 (0.78) & $1.63 \pm 0.56$ & $2.83 \pm 0.88$ & $1.35 \pm 0.27$ & $0.86 \pm 0.25$ & $1.69 \pm 0.53$ \\
\hline$A G+G G$ & 904 & $5.03 \pm 1.01$ & $1.11(0.89)$ & $1.50 \pm 0.45$ & $2.85 \pm 0.79$ & $1.38 \pm 0.31$ & $0.90 \pm 0.22$ & $1.67 \pm 0.66$ \\
\hline$F$ & & 7.760 & -0.274 & 7.746 & 1.515 & 2.958 & 3.173 & 1.525 \\
\hline P & & 0.012 & 0.784 & 0.015 & 0.682 & 0.381 & 0.318 & 0.679 \\
\hline \multicolumn{9}{|c|}{ Maonan/Male } \\
\hline AA & 46 & $4.70 \pm 0.94$ & $0.97(0.57)$ & $1.65 \pm 0.41$ & $2.72 \pm 0.82$ & $1.37 \pm 0.30$ & $0.85 \pm 0.17$ & $1.69 \pm 0.46$ \\
\hline$A G+G G$ & 419 & $4.94 \pm 0.83$ & $1.07(0.76)$ & $1.56 \pm 0.43$ & $2.80 \pm 0.75$ & $1.37 \pm 0.37$ & $0.87 \pm 0.21$ & $1.66 \pm 0.65$ \\
\hline$F$ & & 8.088 & -1.032 & 3.800 & 3.569 & 0.925 & 1.506 & 3.862 \\
\hline$P$ & & 0.004 & 0.302 & 0.205 & 0.256 & 0.963 & 0.553 & 0.226 \\
\hline \multicolumn{9}{|c|}{ Maonan/Female } \\
\hline AA & 263 & $4.87 \pm 1.04$ & $1.15(0.90)$ & $1.59 \pm 0.68$ & $2.89 \pm 0.85$ & $1.34 \pm 0.25$ & $0.87 \pm 0.25$ & $1.69 \pm 0.50$ \\
\hline$A G+G G$ & 485 & $5.08 \pm 1.12$ & $1.27(1.04)$ & $1.45 \pm 0.72$ & $2.95 \pm 0.92$ & $1.39 \pm 0.24$ & $0.92 \pm 0.23$ & $1.69 \pm 0.64$ \\
\hline$F$ & & 7.717 & -1.159 & 7.901 & 3.085 & 7.246 & 6.432 & 0.945 \\
\hline$P$ & & 0.015 & 0.246 & 0.013 & 0.352 & 0.030 & 0.055 & 0.923 \\
\hline \multicolumn{9}{|c|}{ NOTCH4 rs3134931 } \\
\hline \multicolumn{9}{|l|}{ Han } \\
\hline GG & 315 & $4.80 \pm 1.05$ & $0.86(0.82)$ & $1.77 \pm 0.58$ & $2.63 \pm 0.86$ & $1.47 \pm 0.33$ & $0.81 \pm 0.21$ & $1.83 \pm 0.62$ \\
\hline$A G+A A$ & 939 & $4.83 \pm 1.07$ & $1.26(0.88)$ & $1.71 \pm 0.52$ & $2.73 \pm 0.87$ & $1.42 \pm 0.27$ & $0.84 \pm 0.21$ & $1.79 \pm 0.57$ \\
\hline$F$ & & 1.548 & -7.020 & 4.333 & 5.731 & 1.747 & 1.536 & 3.026 \\
\hline$P$ & & 0.524 & 0.000 & 0.114 & 0.074 & 0.481 & 0.532 & 0.341 \\
\hline \multicolumn{9}{|l|}{ Han/Male } \\
\hline GG & 163 & $4.89 \pm 0.97$ & $0.80(0.79)$ & $1.71 \pm 0.69$ & $2.75 \pm 0.86$ & $1.35 \pm 0.29$ & $0.78 \pm 0.21$ & $1.81 \pm 0.52$ \\
\hline$A G+A A$ & 396 & $5.04 \pm 1.04$ & $1.10(0.85)$ & $1.54 \pm 0.41$ & $2.82 \pm 0.79$ & $1.39 \pm 0.23$ & $0.81 \pm 0.21$ & $1.83 \pm 0.45$ \\
\hline$F$ & & 4.416 & -3.528 & 7.696 & 3.123 & 1.416 & 3.924 & 1.458 \\
\hline$P$ & & 0.109 & 0.017 & 0.014 & 0.323 & 0.731 & 0.180 & 0.557 \\
\hline \multicolumn{9}{|l|}{ Han/Female } \\
\hline GG & 152 & $4.68 \pm 1.12$ & $0.98(0.79)$ & $1.83 \pm 0.45$ & $2.62 \pm 0.90$ & $1.60 \pm 0.31$ & $0.83 \pm 0.22$ & $1.90 \pm 0.45$ \\
\hline$A G+A A$ & 543 & $4.68 \pm 1.06$ & $1.30(0.85)$ & $1.87 \pm 0.58$ & $2.67 \pm 0.88$ & $1.48 \pm 0.30$ & $0.89 \pm 0.21$ & $1.73 \pm 0.56$ \\
\hline$F$ & & 0.836 & -4.038 & 2.989 & 1.612 & 5.576 & 2.726 & 2.874 \\
\hline P & & 0.992 & 0.008 & 0.404 & 0.526 & 0.089 & 0.432 & 0.388 \\
\hline \multicolumn{9}{|l|}{ Maonan } \\
\hline GG & 352 & $4.90 \pm 0.91$ & $0.99(0.86)$ & $1.57 \pm 0.43$ & $2.76 \pm 0.80$ & $1.39 \pm 0.25$ & $0.84 \pm 0.20$ & $1.71 \pm 0.48$ \\
\hline
\end{tabular}


Table 4 (continued)

\begin{tabular}{|c|c|c|c|c|c|c|c|c|}
\hline Genotype & $\mathrm{n}$ & $\mathrm{TC}(\mathrm{mmol} / \mathrm{L})$ & $\mathrm{TG}(\mathrm{mmol} / \mathrm{L})$ & $\mathrm{HDL}-\mathrm{C}(\mathrm{mmol} / \mathrm{L})$ & LDL-C (mmol/L) & ApoA1 (g/L) & ApoB (g/L) & ApoA1 /ApoB \\
\hline$A G+A A$ & 861 & $5.03 \pm 1.01$ & $1.34(0.84)$ & $1.55 \pm 0.50$ & $2.92 \pm 0.86$ & $1.36 \pm 0.31$ & $0.90 \pm 0.24$ & $1.65 \pm 0.57$ \\
\hline$F$ & & 7.035 & -4.444 & 1.097 & 7.241 & 3.914 & 2.676 & 1.422 \\
\hline$P$ & & 0.041 & 0.000 & 0.815 & 0.022 & 0.186 & 0.443 & 0.742 \\
\hline \multicolumn{9}{|c|}{ Maonan/Male } \\
\hline GG & 78 & $4.82 \pm 1.02$ & $0.94(0.73)$ & $1.65 \pm 0.45$ & $2.59 \pm 0.79$ & $1.39 \pm 0.27$ & $0.83 \pm 0.25$ & $1.72 \pm 0.45$ \\
\hline$A G+A A$ & 387 & $4.93 \pm 1.05$ & $1.23 \pm 0.81$ & $1.62 \pm 0.37$ & $2.80 \pm 0.83$ & $1.37 \pm 0.38$ & $0.86 \pm 0.34$ & $1.70 \pm 0.47$ \\
\hline$F$ & & 5.128 & -3.872 & 3.968 & 7.463 & 1.506 & 1.578 & 1.433 \\
\hline$P$ & & 0.088 & 0.012 & 0.167 & 0.016 & 0.543 & 0.528 & 0.634 \\
\hline \multicolumn{9}{|c|}{ Maonan/Female } \\
\hline GG & 274 & $5.04 \pm 1.11$ & 1.05 (0.70) & $1.52 \pm 0.43$ & $2.81 \pm 0.72$ & $1.39 \pm 0.33$ & $0.85 \pm 0.23$ & $1.70 \pm 0.45$ \\
\hline$A G+A A$ & 474 & $5.12 \pm 1.20$ & $1.40(0.80)$ & $1.40 \pm 0.52$ & $3.04 \pm 0.80$ & $1.36 \pm 0.29$ & $0.92 \pm 0.30$ & $1.63 \pm 0.43$ \\
\hline$F$ & & 4.003 & -4.569 & 7.087 & 7.982 & 3.756 & 2.973 & 2.823 \\
\hline$P$ & & 0.125 & 0.000 & 0.017 & 0.008 & 0.195 & 0.358 & 0.427 \\
\hline
\end{tabular}

The value of triglyceride was presented as median (interquartile range) for not meet the normal distribution, the difference among the genotypes was determined by the Kruskal-Wallis test. The $P$ value calculated by ANCOVA, using general linear models, and adjusted for age, sex, BMI, smoking status, alcohol use, glucose and hypertension, $P<0.025$ was considered statistically significant (corresponding to $P<0.05$ after adjusting for 2 independent tests by the Bonferroni correction). $\mathrm{n}=$ sample size

$T C$ total cholesterol, TG triglyceride, HDL-C high-density lipoprotein cholesterol, $L D L-C$ low-density lipoprotein cholesterol, $A p o A 1$ apolipoprotein $\mathrm{A} 1, A p o B$ apolipoprotein $\mathrm{B}, A p o A 1 / A p o B$ the ratio of apolipoprotein $\mathrm{A} 1$ to apolipoprotein $\mathrm{B}$

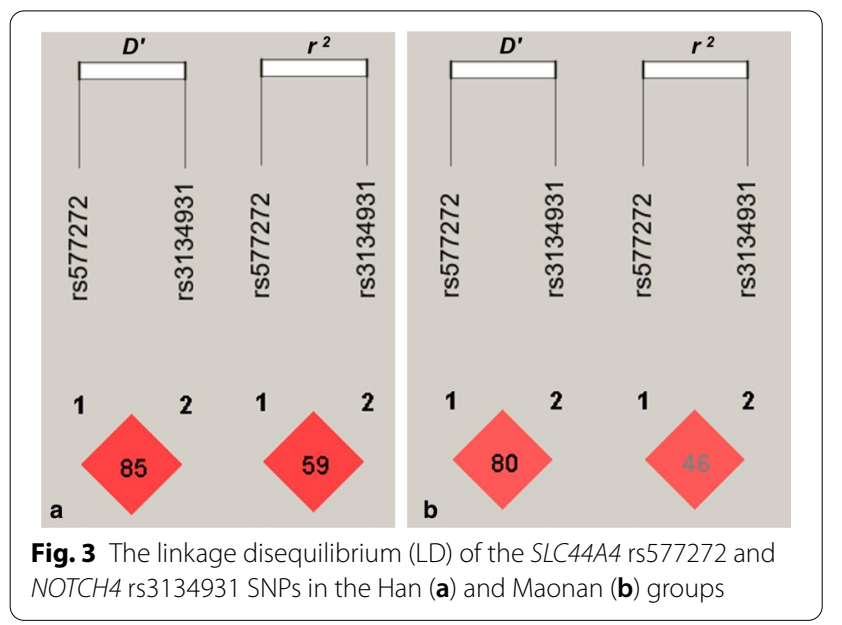

of atherosclerotic plaque and its clinical sequelae [5052]. Although, the potential association between the SLC44A4 rs577272, NOTCH4 rs3134931 SNPs and blood lipid parameters was not previously documented in the Maonan population, the results of the current research clearly indicated that the levels of TC were higher and those of HDL-C were lower in the rs577272G allele carriers than in the rs577272G allele non-carriers in Maonan ethnic group. Meanwhile, the rs3134931A allele carriers had higher TG levels in Han nationality and higher TG and LDL-C levels in Maonan ethnic group than the rs3134931A allele non-carriers.

Important inter-genetic LD associations were also found in the current study. A strong linkage imbalance was detected between the two loci in both Han and

Table 5 Association between the haplotypes among SLC44A4 rs577272 SNP and NOTCH4 rs3134931 SNP andHLP in the Han and Maonan group [n(frequency)]

\begin{tabular}{|c|c|c|c|c|c|c|c|c|c|}
\hline No & Haplotypes & Han & & & & Maonan & & & \\
\hline & & Normal & HLP & OR [95\% Cl] & $P$ value & Normal & HLP & OR [95\% Cl] & $P$ value \\
\hline S1 & rs577272A-rs3134931A & $\begin{array}{l}395.94 \\
(0.284)\end{array}$ & $\begin{array}{l}361.33 \\
(0.260)\end{array}$ & $\begin{array}{l}0.930 \\
{[0.868-1.221]}\end{array}$ & 0.4376 & $\begin{array}{l}239.27 \\
(0.208)\end{array}$ & $\begin{array}{l}273.27 \\
(0.192)\end{array}$ & $\begin{array}{l}0.914 \\
{[1.024-1.201]}\end{array}$ & 0.7876 \\
\hline S2 & rs577272A-rs3134931G & $\begin{array}{l}363.81 \\
(0.261)\end{array}$ & $\begin{array}{l}302.59 \\
(0.218)\end{array}$ & $\begin{array}{l}0.910 \\
{[0.758-1.082]}\end{array}$ & 0.1756 & $\begin{array}{l}392.64 \\
(0.341)\end{array}$ & $\begin{array}{l}373.69 \\
(0.263)\end{array}$ & $\begin{array}{l}0.849 \\
{[0.742-1.034]}\end{array}$ & 0.1700 \\
\hline S3 & rs577272G-rs3134931A & $\begin{array}{l}284.85 \\
(0.204)\end{array}$ & $\begin{array}{l}379.42 \\
(0.275)\end{array}$ & $\begin{array}{l}2.289 \\
{[2.017-2.620]}\end{array}$ & 0.0021 & $\begin{array}{l}251.94 \\
(0.219)\end{array}$ & $\begin{array}{l}453.62 \\
(0.320)\end{array}$ & $\begin{array}{l}2.442 \\
{[2.229-2.698]}\end{array}$ & 0.0011 \\
\hline S4 & rs577272G-rs3134931G & $\begin{array}{l}350.99 \\
(0.251)\end{array}$ & $\begin{array}{l}342.61 \\
(0.247)\end{array}$ & $\begin{array}{l}0.906 \\
{[0.741-1.026]}\end{array}$ & 0.5580 & $\begin{array}{l}267.15 \\
(0.232)\end{array}$ & $\begin{array}{l}319.23 \\
(0.225)\end{array}$ & $\begin{array}{l}0.917 \\
{[0.879-1.258]}\end{array}$ & 0.6540 \\
\hline
\end{tabular}

Rare Hap (frequency $<1 \%$ ) in both populations has been dropped. $P$ was obtained by unconditional logistic regression analysis

HLP hyperlipidaemia, SLC44A4 solute carrier family 44 member 4 , NOTCH4 notch receptor 4 


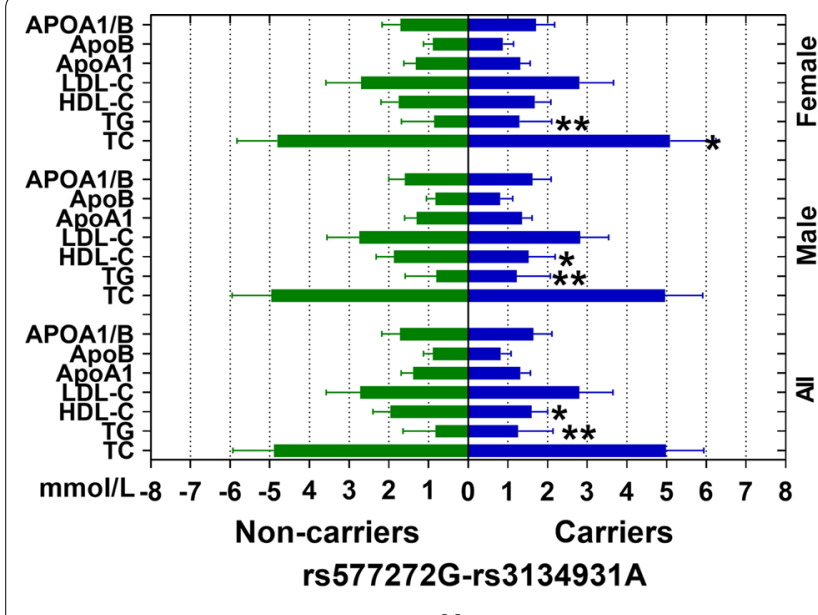

Han

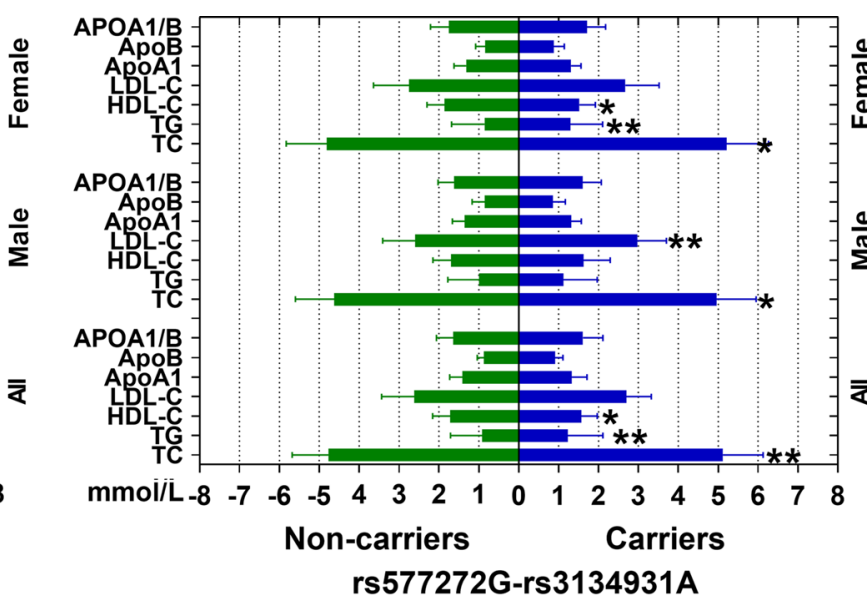

Maonan

Fig. 4 Lipid parameters according to the haplotypes of the Han and Maonan groups. TC total cholesterol, TG triglyceride, HDL-C high-density lipoprotein cholesterol, LDL-C low-density lipoprotein cholesterol, Apo apolipoprotein. ${ }^{*} P<0.05 ;^{* *} P<0.001$

Table 6 The SLC44A4 rs577272G-NOTCH4 rs3134931A haplotype and HLP in the Han and Maonan populations according to stratified risk factors

\begin{tabular}{|c|c|c|c|c|c|c|}
\hline Factor & Type & Haplotype & OR $(95 \% \mathrm{Cl})_{\text {Han }}$ & $P_{\text {Han }}$ & OR $(95 \% \mathrm{Cl})_{\text {Maonan }}$ & $P_{\text {Maonan }}$ \\
\hline \multirow[t]{2}{*}{ Gender } & Male & G-A non-carriers & 1 & - & 1 & - \\
\hline & Female & G-A carriers & $1.629(1.176-2.257)$ & 0.003 & $1.721(1.223-2.451)$ & 0.023 \\
\hline \multirow[t]{2}{*}{$\mathrm{BMl}$} & $<24 \mathrm{~kg} / \mathrm{m}^{2}$ & G-A non-carriers & 1 & - & 1 & - \\
\hline & $\geq 24 \mathrm{~kg} / \mathrm{m}$ & G-A carriers & $3.163(1.976-4.064)$ & $1.61 E-6$ & $3.413(3.117-3.867)$ & $2.01 \mathrm{E}-6$ \\
\hline \multirow[t]{2}{*}{ Smoking } & Nonsmoker & G-A non-carriers & 1 & - & 1 & - \\
\hline & Smoker & G-A carriers & $2.412(1.862-2.871)$ & $1.48 \mathrm{E}-5$ & $2.651(1.935-3.312)$ & $2.20 \mathrm{E}-6$ \\
\hline \multirow[t]{2}{*}{ Drinking } & Nondrinker & G-A non-carriers & 1 & - & 1 & - \\
\hline & Drinker & G-A carriers & $0.859(0.635-1.163)$ & 0.326 & $0.912(0.712-1.221)$ & 0.412 \\
\hline \multirow[t]{2}{*}{ Diabetes } & Non-diabetes & G-A non-carriers & 1 & - & 1 & - \\
\hline & Diabetes & G-A carriers & $2.802(2.208-3.390)$ & $2.52 \mathrm{E}-5$ & $2.445(2.037-3.088)$ & $1.15 E-5$ \\
\hline \multirow[t]{2}{*}{ Blood pressure } & Normotensive & G-A non-carriers & 1 & - & 1 & - \\
\hline & Hypertension & G-A carriers & $2.234(1.782-2.653)$ & $6.12 \mathrm{E}-4$ & $2.534(1.982-2.853)$ & $4.22 \mathrm{E}-4$ \\
\hline
\end{tabular}

Maonan ethnic groups. The haplotype of rs577272Grs3134931A was the commonest one and accounted for more than $50 \%$ of the samples. The haplotype of the rs577272G-rs3134931A was related to an increased morbidity of HLP in the both Han and Maonan groups. At the same time, the haplotype of rs577272G-rs3134931A was associated with TG and HDL-C levels in Han; TC, TG and HDL-C levels in Maonan ethnic groups. We also noticed that haplotypes could explain more changes in serum lipid parameters than any single SNP alone particularly for TC, TG and HDL-C.

Previous studies indicated that several environmental factors were significantly associated with blood lipid spectrums, including hypertension, obesity, daily exercise, diet and lifestyle [53-56]. In the current study, we also noticed that there was association between BMI, age, blood pressure, alcohol consumption, gender, cigarette smoking and serum lipid levels in both Han and Maonan ethnic groups, suggesting that several environmental factors may also play a crucial role in influencing serum lipid levels. The marriage custom, dietary habits and lifestyle were significantly different between Han and Maonan populations. The marriage custom in Maonan is relatively conservative. Parents mainly arrange their marriages. The people of Maonan still maintain the custom of intra-ethnic marriages. Thus, intermarriage with other ethnic groups is very rare. This may be the main reason why the genetic characteristics and genotype frequencies of some lipid metabolism-related SNPs were different between the Maonan and Han populations. 
Table 7 Correlation between serum lipid parameters and the SLC44A4 rs577272 SNP and NOTCH4 rs3134931 SNP alleles/ genotypes in the Han and Maonan populations

\begin{tabular}{|c|c|c|c|c|c|c|c|}
\hline Lipid & SNP & Allele & Genotype & Std.error & Beta & $t$ & $P$ \\
\hline \multicolumn{8}{|c|}{ Han + Maonan } \\
\hline \multirow[t]{2}{*}{$\mathrm{TC}$} & rs577272 & $\mathrm{A} / \mathrm{G}$ & & 0.009 & -0.027 & -3.169 & 0.002 \\
\hline & rs577272 & & $\mathrm{AA} / \mathrm{GA} / \mathrm{GG}$ & 0.019 & 0.065 & 3.394 & 0.001 \\
\hline \multirow[t]{2}{*}{ TG } & rs3134931 & $\mathrm{G} / \mathrm{A}$ & & 0.068 & -0.236 & -3.495 & $4.92 \mathrm{E}-4$ \\
\hline & & & GG/AG/AA & 0.077 & -0.212 & -2.749 & 0.006 \\
\hline $\mathrm{HDL}-\mathrm{C}$ & rs577272 & & $\mathrm{AA} / \mathrm{GA} / \mathrm{GG}$ & 0.043 & 0.112 & 2.580 & 0.010 \\
\hline LDL-C & rs3134931 & & $\mathrm{AA} / \mathrm{GA} / \mathrm{GG}$ & 0.021 & -0.071 & -3.395 & 0.001 \\
\hline \multicolumn{8}{|l|}{ Han } \\
\hline TC & rs577272 & $\mathrm{A} / \mathrm{G}$ & & 0.065 & 0.117 & 2.717 & 0.007 \\
\hline \multirow[t]{2}{*}{$\mathrm{TG}$} & rs3134931 & $\mathrm{G} / \mathrm{A}$ & & 0.068 & -0.236 & -3.495 & 4.913E-4 \\
\hline & & & GG/AG/AA & 0.019 & 0.065 & 3.394 & 0.001 \\
\hline \multirow[t]{2}{*}{ HDL-C } & rs3134931 & $\mathrm{G} / \mathrm{A}$ & & 0.091 & -0.359 & -3.958 & $7.95 \mathrm{E}-5$ \\
\hline & rs577272 & $\mathrm{A} / \mathrm{G}$ & & 0.137 & 0.276 & 2.014 & 0.044 \\
\hline \multicolumn{8}{|l|}{ Maonan } \\
\hline \multirow[t]{2}{*}{$\mathrm{TC}$} & rs577272 & $\mathrm{A} / \mathrm{G}$ & & 0.092 & 0.527 & 6.103 & $9.24 \mathrm{E}-10$ \\
\hline & rs577272 & & $\mathrm{AA} / \mathrm{GA} / \mathrm{GG}$ & 0.069 & -0.305 & -4.437 & $9.33 \mathrm{E}-6$ \\
\hline \multirow[t]{2}{*}{$\mathrm{TG}$} & rs3134931 & $\mathrm{G} / \mathrm{A}$ & & 0.064 & -0.199 & -3.091 & 0.004 \\
\hline & rs3134931 & & $\mathrm{AA} / \mathrm{GA} / \mathrm{GG}$ & 0.049 & -0.128 & -2.628 & 0.008 \\
\hline \multirow[t]{3}{*}{ HDL-C } & rs577272 & & $\mathrm{AA} / \mathrm{GA} / \mathrm{GG}$ & 0.035 & -0.119 & -3.754 & $1.83 \mathrm{E}-4$ \\
\hline & rs577272 & $\mathrm{A} / \mathrm{G}$ & & 0.058 & -0.16 & -2.725 & 0.006 \\
\hline & rs3134931 & $\mathrm{G} / \mathrm{A}$ & & 0.031 & -0.094 & -3.236 & 0.002 \\
\hline \multirow[t]{2}{*}{ LDL-C } & rs3134931 & & $\mathrm{AA} / \mathrm{GA} / \mathrm{GG}$ & 0.093 & 0.567 & 6.123 & $9.04 \mathrm{E}-10$ \\
\hline & rs3134931 & $\mathrm{G} / \mathrm{A}$ & & 0.069 & -0.305 & -4.417 & $4.83 \mathrm{E}-6$ \\
\hline
\end{tabular}

Association of serum lipid traits and allele and genotypes in Maonan, Han and combined the Maonan and Han populations were assessed by multivariable linear regression analyses with stepwise modeling

TC total cholesterol, HDL-C high-density lipoprotein cholesterol, Apo apolipoprotein, Beta standardized coefficient

Rice acts as a staple food of Maonan people. In addition, corn, potato, wheat, sorghum and so on are also be components of their diet. Maonan people especially like to eat some food that rich of oil, spicy, acid and salt. This type of diet rich in long-term high saturated fat might contribute to obesity, hypertension, high blood glucose levels, atherosclerosis and HLP [57]. Previous research has proven that the diet rich in longterm high saturated fat might contribute to a series of harmful effects on the metabolism of blood lipids, especially increased the levels of TG and TC [58]. A clinical study suggested that different doses of alcohol intake might have diverse effects on the development of atherosclerosis [59]. Several compelling researches have suggested that moderate drinking could reduce the incidence of cardiovascular events, the potential mechanism may be associated with the increased levels of HDL-C and ApoA1 [60]. However, frequent binge drinking was correlated with an increased risk of CHD mortality because it will lead to a number of serious health problems including dyslipidaemia, abnormal liver function and MI [61]. A series of recent researches also have proven that excessive drinking [57] and smoking $[62,63]$ were directly related to the occurrence and development of HLP. In this study, we noticed that the number of subjects who consumed alcohol and smoked were greater in Maonan than in Han groups and the number of subjects who smoked or consumed alcohol were greater in HLP than in normal groups. Thus, the combined effects of lifestyle factors, various eating habits and environmental aspects perhaps further alter the relationship of hereditary variations and serum lipid levels observed in the current research.

This study may have several limitations. To begin with, in the statistical analysis, we were not in a position to mitigate the effects of diet and some environmental factors. Secondly, other serum lipid parameters such as HDL2, small dense LDL, large buoyant LDL etc. 
Table 8 Relationship between serum lipid parameters and relative factors in the Han and Maonan populations

\begin{tabular}{|c|c|c|c|c|c|c|}
\hline Lipid & Risk factor & B & Std.error & Beta & $t$ & $P$ \\
\hline \multicolumn{7}{|c|}{ Han and Maonan } \\
\hline \multirow[t]{6}{*}{ TC } & Waist circumference & 0.021 & 0.003 & 0.173 & 7.626 & $3.63 \mathrm{E}-4$ \\
\hline & Diastolic blood pressure & 0.010 & 0.002 & 0.117 & 5.290 & $1.35 \mathrm{E}-7$ \\
\hline & Age & 0.007 & 0.002 & 0.086 & 3.962 & $7.69 \mathrm{E}-5$ \\
\hline & Height & -0.013 & 0.003 & -0.094 & -3.923 & $9.02 \mathrm{E}-5$ \\
\hline & Cigarette smoking & 0.130 & 0.050 & 0.059 & 2.610 & 0.009 \\
\hline & Ethnic group & 0.103 & 0.045 & 0.048 & 2.285 & 0.022 \\
\hline \multirow[t]{3}{*}{$\mathrm{TG}$} & Pulse pressure & -0.004 & 0.001 & 0.072 & -3.311 & 0.001 \\
\hline & Cigarette smoking & -0.116 & 0.056 & 0.055 & -2.068 & 0.039 \\
\hline & Height & -0.010 & 0.003 & -0.093 & -3.596 & $3.30 \mathrm{E}-4$ \\
\hline \multirow[t]{3}{*}{$\mathrm{HDL}-\mathrm{C}$} & Ethnic group & -0.194 & 0.023 & -0.176 & -8.325 & $1.49 \mathrm{E}-6$ \\
\hline & Weight & 0.005 & 0.001 & 0.090 & -3.921 & $9.10 \mathrm{E}-5$ \\
\hline & Gender & 0.089 & 0.026 & 0.079 & 3.420 & 0.001 \\
\hline \multirow[t]{3}{*}{ LDL-C } & Waist circumference & 0.018 & 0.002 & 0.190 & 8.407 & $7.62 \mathrm{E}-17$ \\
\hline & Alcohol consumption & -0.209 & 0.033 & -0.156 & -6.379 & $2.19 \mathrm{E}-10$ \\
\hline & Ethnic group & -0.004 & 0.001 & -0.100 & -3.758 & $1.76 \mathrm{E}-4$ \\
\hline \multirow[t]{4}{*}{ ApoA1 } & Alcohol consumption & 0.131 & 0.011 & 0.280 & 11.464 & $1.46 \mathrm{E}-9$ \\
\hline & Cigarette smoking & 0.117 & 0.016 & 0.192 & 7.441 & $1.44 \mathrm{E}-13$ \\
\hline & Weight & -0.002 & 0.001 & -0.074 & -2.269 & 0.023 \\
\hline & Waist circumference & -0.002 & 0.001 & -0.074 & -2.399 & 0.017 \\
\hline \multirow[t]{3}{*}{ ApoB } & Waist circumference & 0.007 & 0.001 & 0.294 & 13.301 & $7.78 \mathrm{E}-9$ \\
\hline & Systolic blood pressure & 0.001 & 0.000 & 0.100 & 4.735 & $2.34 \mathrm{E}-6$ \\
\hline & Height & -0.002 & 0.001 & -0.052 & -2.417 & 0.016 \\
\hline \multirow[t]{3}{*}{ ApoA1/ApoB } & Waist circumference & -0.019 & 0.001 & -0.274 & -13.042 & $1.87 \mathrm{E}-37$ \\
\hline & Alcohol consumption & 0.160 & 0.024 & 0.166 & 6.711 & $2.47 \mathrm{E}-11$ \\
\hline & Cigarette smoking & 0.167 & 0.033 & 0.134 & 5.132 & $3.12 \mathrm{E}-7$ \\
\hline \multicolumn{7}{|l|}{ Han } \\
\hline \multirow[t]{4}{*}{$\mathrm{TC}$} & Diastolic blood pressure & 0.017 & 0.003 & 0.192 & 6.289 & $4.70 E-10$ \\
\hline & Waist circumference & 0.016 & 0.004 & 0.121 & 3.823 & $1.40 \mathrm{E}-4$ \\
\hline & Glucose & 0.056 & 0.019 & 0.087 & 2.919 & 0.004 \\
\hline & Gender & -0.010 & 0.005 & -0.076 & -2.265 & 0.024 \\
\hline \multirow[t]{3}{*}{ TG } & Glucose & 0.036 & 0.016 & 0.068 & 2.225 & 0.026 \\
\hline & Cigarette smoking & -0.125 & 0.051 & -0.075 & -2.449 & 0.014 \\
\hline & Pulse pressure & -0.007 & 0.002 & -0.138 & -4.510 & $7.21 \mathrm{E}-6$ \\
\hline \multirow[t]{3}{*}{ HDL-C } & Weight & -0.015 & 0.002 & -0.238 & -7.359 & $3.74 \mathrm{E}-4$ \\
\hline & Alcohol consumption & 0.097 & 0.028 & 0.113 & 3.501 & $4.83 \mathrm{E}-4$ \\
\hline & Gender & -0.005 & 0.002 & -0.098 & -2.538 & 0.011 \\
\hline \multirow[t]{3}{*}{ LDL-C } & Waist circumference & 0.016 & 0.003 & 0.148 & 4.846 & $1.45 \mathrm{E}-6$ \\
\hline & Systolic blood pressure & 0.008 & 0.002 & 0.194 & 5.417 & $7.53 \mathrm{E}-8$ \\
\hline & Age & -0.006 & 0.001 & -0.147 & -4.213 & $2.73 E-5$ \\
\hline \multirow[t]{3}{*}{ ApoA1 } & Alcohol consumption & 0.189 & 0.014 & 0.423 & 13.732 & $1.38 \mathrm{E}-9$ \\
\hline & Cigarette smoking & 0.143 & 0.017 & 0.255 & 8.598 & $2.90 \mathrm{E}-7$ \\
\hline & Weight & -0.006 & 0.001 & -0.174 & -6.225 & $6.93 \mathrm{E}-10$ \\
\hline \multirow[t]{3}{*}{ ApoB } & Waist circumference & 0.006 & 0.001 & 0.224 & 5.731 & $1.30 \mathrm{E}-8$ \\
\hline & Glucose & 0.012 & 0.004 & 0.092 & 3.165 & 0.002 \\
\hline & $\mathrm{BMI}$ & 0.005 & 0.002 & 0.085 & 2.227 & 0.026 \\
\hline \multirow[t]{3}{*}{ ApoA1/ApoB } & Waist circumference & -0.013 & 0.003 & -0.168 & -3.744 & $1.91 \mathrm{E}-4$ \\
\hline & Alcohol consumption & 0.204 & 0.033 & 0.222 & 6.239 & $6.39 E-10$ \\
\hline & Cigarette smoking & 0.204 & 0.043 & 0.176 & 4.798 & $1.84 \mathrm{E}-6$ \\
\hline
\end{tabular}


Table 8 (continued)

\begin{tabular}{|c|c|c|c|c|c|c|}
\hline Lipid & Risk factor & B & Std.error & Beta & $t$ & $P$ \\
\hline \multicolumn{7}{|l|}{ Maonan } \\
\hline \multirow[t]{4}{*}{$\mathrm{TC}$} & Waist circumference & 0.023 & 0.004 & 0.202 & 6.206 & 0.000 \\
\hline & Age & 0.007 & 0.002 & 0.103 & 3.302 & 0.001 \\
\hline & Diastolic blood pressure & 0.005 & 0.003 & 0.062 & 1.966 & 0.050 \\
\hline & Height & -0.010 & 0.005 & -0.076 & -2.265 & 0.024 \\
\hline \multirow[t]{3}{*}{ TG } & Alcohol consumption & 0.178 & 0.060 & 0.108 & 2.980 & 0.003 \\
\hline & Cigarette smoking & -0.183 & 0.086 & -0.082 & -2.125 & 0.034 \\
\hline & Weight & -0.015 & 0.002 & -0.238 & -7.359 & $3.74 E-13$ \\
\hline \multirow[t]{2}{*}{$\mathrm{HDL}-\mathrm{C}$} & Gender & 0.158 & 0.042 & 0.143 & 3.783 & $1.64 \mathrm{E}-4$ \\
\hline & Systolic blood pressure & 0.002 & 0.001 & 0.087 & 2.835 & 0.005 \\
\hline \multirow[t]{3}{*}{ LDL-C } & Alcohol consumption & -0.310 & 0.039 & -0.231 & -7.920 & $5.92 \mathrm{E}-5$ \\
\hline & Waist circumference & 0.017 & 0.003 & 0.194 & 6.633 & $5.21 \mathrm{E}-5$ \\
\hline & Age & 0.008 & 0.002 & 0.140 & 4.856 & $1.38 \mathrm{E}-6$ \\
\hline \multirow[t]{3}{*}{ ApoA1 } & Waist circumference & -0.004 & 0.001 & -0.143 & -4.708 & $2.83 \mathrm{E}-6$ \\
\hline & Alcohol consumption & 0.071 & 0.015 & 0.147 & 4.855 & $1.38 \mathrm{E}-6$ \\
\hline & Glucose & 0.014 & 0.06 & 0.067 & -2.227 & 0.026 \\
\hline \multirow[t]{3}{*}{ ApoB } & Waist circumference & 0.007 & 0.001 & 0.297 & 9.806 & $8.51 \mathrm{E}-6$ \\
\hline & Age & 0.001 & 0.000 & 0.071 & 2.197 & 0.028 \\
\hline & Pulse pressure & 0.001 & 0.000 & 0.070 & 2.133 & 0.033 \\
\hline \multirow[t]{3}{*}{ ApoA1/ApoB } & Waist circumference & -0.017 & 0.002 & -0.261 & -8.784 & $6.16 \mathrm{E}-8$ \\
\hline & Alcohol consumption & 0.161 & 0.029 & 0.163 & 5.552 & $3.56 \mathrm{E}-8$ \\
\hline & Pulse pressure & -0.003 & 0.001 & -0.095 & -3.234 & 0.001 \\
\hline
\end{tabular}

TC total cholesterol, TG triglyceride, $H D L-C$ high-density lipoprotein cholesterol, $L D L-C$ low-density lipoprotein cholesterol, $A p o A 1$ apolipoprotein $\mathrm{A} 1, A p o B$ apolipoprotein $B, A p o A 1 / A p o B$ the ratio of apolipoprotein $A 1$ to apolipoprotein $B, B$ unstandardized coefficient, Beta standardized coefficient

had not been measured in our study. Thirdly, regardless of the fact that we observe a significantly correlation between the SLC44A4 rs577272, NOTCH4 rs3134931 SNPs and serum lipid levels, other genomic as well as environmental factors are necessary to be considered. The future studies need to be done to study the effects of either gene-gene or gene-environment or environmentenvironment on serum lipid levels. In order to further demonstrate our findings, some efficient studies on the natural functions of the SLC44A4 rs577272 and NOTCH4 rs3134931 mutations are essential.

\section{Conclusions}

The associations of the SLC44A4 rs577272, NOTCH4 rs3134931 SNPs and serum lipid levels were not similar between Han and Maonan populations as well as among men and women in both ethnic groups. There might be a race- and/or gender-specific relationship 
Table 9 Relationship between serum lipid parameters and relative factors in the males and females of the Han and Maonan populations

\begin{tabular}{|c|c|c|c|c|c|c|}
\hline Lipid & Risk factor & B & Std.error & Beta & $t$ & $P$ \\
\hline \multicolumn{7}{|l|}{ Han/male } \\
\hline \multirow[t]{2}{*}{ TC } & Waist circumference & 0.016 & 0.006 & 0.123 & 2.640 & 0.009 \\
\hline & Glucose & 0.060 & 0.028 & 0.098 & 2.126 & 0.034 \\
\hline \multirow[t]{2}{*}{ TG } & BMI & 0.006 & 0.003 & 0.111 & 2.073 & 0.037 \\
\hline & Weight & -0.015 & 0.005 & -0.222 & -3.139 & 0.002 \\
\hline \multirow{2}{*}{ HDL-C } & Weight & -0.018 & 0.003 & -0.307 & -6.477 & $2.54 \mathrm{E}-10$ \\
\hline & Alcohol consumption & 0.102 & 0.031 & 0.158 & 3.327 & 0.001 \\
\hline \multirow[t]{3}{*}{ LDL-C } & Cigarette smoking & -0.187 & 0.064 & -0.137 & -2.911 & 0.004 \\
\hline & BMI & 0.031 & 0.010 & 0.142 & 3.052 & 0.002 \\
\hline & Glucose & 0.057 & 0.024 & 0.114 & 2.420 & 0.016 \\
\hline \multirow[t]{2}{*}{ ApoA1 } & Alcohol consumption & 0.197 & 0.015 & 0.519 & 12.809 & $4.48 \mathrm{E}-7$ \\
\hline & Weight & -0.005 & 0.001 & -0.142 & -3.648 & $2.97 \mathrm{E}-4$ \\
\hline \multirow[t]{2}{*}{ ApoB } & Waist circumference & 0.007 & 0.001 & 0.262 & 4.837 & $1.83 \mathrm{E}-6$ \\
\hline & Glucose & 0.020 & 0.006 & 0.152 & 3.472 & 0.001 \\
\hline \multirow[t]{2}{*}{ ApoA1/ApoB } & Waist circumference & -0.011 & 0.005 & -0.147 & -2.121 & 0.035 \\
\hline & Alcohol consumption & 0.221 & 0.034 & 0.300 & 6.572 & $1.44 \mathrm{E}-9$ \\
\hline \multicolumn{7}{|l|}{ Han/female } \\
\hline \multirow[t]{2}{*}{ TC } & Systolic blood pressure & 0.011 & 0.003 & 0.192 & 3.394 & 0.001 \\
\hline & Age & 0.009 & 0.003 & 0.106 & 2.437 & 0.015 \\
\hline \multirow[t]{2}{*}{ TG } & Height & -0.014 & 0.006 & -0.091 & -2.242 & 0.025 \\
\hline & Waist circumference & 0.019 & 0.006 & 0.128 & 3.055 & 0.002 \\
\hline \multirow[t]{2}{*}{ HDL-C } & Waist circumference & -0.011 & 0.003 & -0.142 & -3.563 & $3.95 \mathrm{E}-4$ \\
\hline & Pulse pressure & 0.002 & 0.001 & 0.109 & 2.803 & 0.005 \\
\hline \multirow[t]{2}{*}{ LDL-C } & Systolic blood pressure & 0.005 & 0.002 & 0.107 & 2.566 & 0.011 \\
\hline & Waist circumference & 0.018 & 0.005 & 0.149 & 3.745 & $1.91 \mathrm{E}-4$ \\
\hline \multirow[t]{2}{*}{ ApoA1 } & Cigarette smoking & 0.317 & 0.057 & 0.215 & 5.558 & 4.07E-8 \\
\hline & Weight & -0.005 & 0.001 & -0.152 & -3.907 & $1.04 \mathrm{E}-4$ \\
\hline \multirow[t]{2}{*}{ ApoB } & Waist circumference & 0.007 & 0.001 & 0.240 & 6.191 & $1.09 \mathrm{E}-9$ \\
\hline & Pulse pressure & 0.002 & 0.001 & 0.141 & 3.643 & $2.92 \mathrm{E}-4$ \\
\hline \multirow[t]{2}{*}{ ApoA1/ApoB } & Waist circumference & -0.016 & 0.003 & -0.202 & -5.172 & $3.14 \mathrm{E}-7$ \\
\hline & Cigarette smoking & 0.580 & 0.137 & 0.165 & 4.225 & $2.75 \mathrm{E}-5$ \\
\hline \multicolumn{7}{|l|}{ Maonan/male } \\
\hline \multirow[t]{2}{*}{$\mathrm{TC}$} & Waist circumference & -0.012 & 0.001 & -0.276 & -8.270 & $5.04 \mathrm{E}-6$ \\
\hline & Alcohol consumption & 0.131 & 0.023 & 0.206 & 5.594 & $2.98 \mathrm{E}-8$ \\
\hline \multirow[t]{3}{*}{$\mathrm{TG}$} & Waist circumference & -0.019 & 0.002 & -0.311 & -9.736 & $2.53 \mathrm{E}-7$ \\
\hline & Weight & 0.010 & 0.004 & 0.114 & 2.541 & 0.005 \\
\hline & Genotype & -0.06 & 0.026 & -0.073 & -2.313 & 0.021 \\
\hline \multirow[t]{2}{*}{ HDL-C } & Pulse pressure & -0.002 & 0.001 & -0.078 & -2.202 & 0.028 \\
\hline & Alcohol consumption & 0.057 & 0.048 & 0.113 & 3.801 & $5.23 \mathrm{E}-4$ \\
\hline \multirow[t]{2}{*}{ LDL-C } & Weight & 0.013 & 0.004 & 0.170 & 3.589 & $3.61 \mathrm{E}-4$ \\
\hline & Alcohol consumption & 0.121 & 0.022 & 0.265 & 5.579 & $4.48 \mathrm{E}-8$ \\
\hline ApoA1 & Waist circumference & -0.007 & 0.002 & -0.165 & -3.486 & 0.001 \\
\hline & Glucose & -0.026 & 0.012 & -0.103 & -2.163 & 0.031 \\
\hline ApoB & Alcohol consumption & -0.029 & 0.011 & -0.122 & -2.670 & 0.008 \\
\hline & Age & 0.001 & 0.001 & 0.095 & 2.000 & 0.046 \\
\hline ApoA1/ApoB & Waist circumference & -0.021 & 0.003 & -0.293 & -6.435 & $3.56 \mathrm{E}-10$ \\
\hline & Glucose & -0.043 & 0.021 & -0.093 & -2.032 & 0.043 \\
\hline Maonan/female & Age & 0.015 & 0.003 & 0.193 & 4.788 & $2.08 \mathrm{E}-6$ \\
\hline
\end{tabular}


Table 9 (continued)

\begin{tabular}{|c|c|c|c|c|c|c|}
\hline Lipid & Risk factor & B & Std.error & Beta & $t$ & $P$ \\
\hline \multirow[t]{2}{*}{$\mathrm{TC}$} & Waist circumference & 0.019 & 0.005 & 0.153 & 3.852 & $1.28 \mathrm{E}-4$ \\
\hline & Glucose & -0.077 & 0.031 & -0.095 & -2.459 & 0.014 \\
\hline \multirow[t]{2}{*}{$\mathrm{TG}$} & $\mathrm{BMI}$ & 0.156 & 0.049 & 0.122 & 3.183 & 0.002 \\
\hline & Alcohol consumption & 0.471 & 0.165 & 0.109 & 2.862 & 0.004 \\
\hline \multirow[t]{2}{*}{ HDL-C } & Weight & 0.002 & 0.001 & 0.093 & 2.676 & 0.008 \\
\hline & Alcohol consumption & -1.066 & 0.152 & -0.252 & -7.014 & $5.68 \mathrm{E}-12$ \\
\hline \multirow[t]{2}{*}{ LDL-C } & Waist circumference & 0.022 & 0.003 & 0.242 & 6.552 & $1.13 E-10$ \\
\hline & Alcohol consumption & -0.312 & 0.044 & -0.260 & -7.023 & $5.35 E-12$ \\
\hline \multirow[t]{2}{*}{ ApoA1 } & $\mathrm{BMl}$ & -0.006 & 0.002 & -0.100 & -2.708 & 0.007 \\
\hline & Waist circumference & 0.496 & 0.042 & 0.399 & 11.810 & $2.27 \mathrm{E}-9$ \\
\hline \multirow[t]{2}{*}{ ApoB } & Waist circumference & 0.005 & 0.001 & 0.185 & 5.353 & $1.19 \mathrm{E}-7$ \\
\hline & Alcohol consumption & -0.687 & 0.101 & -0.243 & -6.786 & $2.54 \mathrm{E}-11$ \\
\hline ApoA1/ApoB & Waist circumference & -0.011 & 0.002 & -0.182 & -4.942 & $9.79 \mathrm{E}-7$ \\
\hline
\end{tabular}

The correlation among serum lipid parameters and the genotypes and several environmental factors was determined by multivariable linear regression analyses with stepwise modeling

$T C$ total cholesterol, TG triglyceride, $H D L-C$ high-density lipoprotein cholesterol, $L D L-C$ low-density lipoprotein cholesterol, $A p o A 1$ apolipoprotein $A 1, A p o B$ apolipoprotein $\mathrm{B}, A p \circ A 1 / A p o B$ the ratio of apolipoprotein $\mathrm{A} 1$ to apolipoprotein $\mathrm{B}, \mathrm{B}$ unstandardized coefficient, Beta standardized coefficient

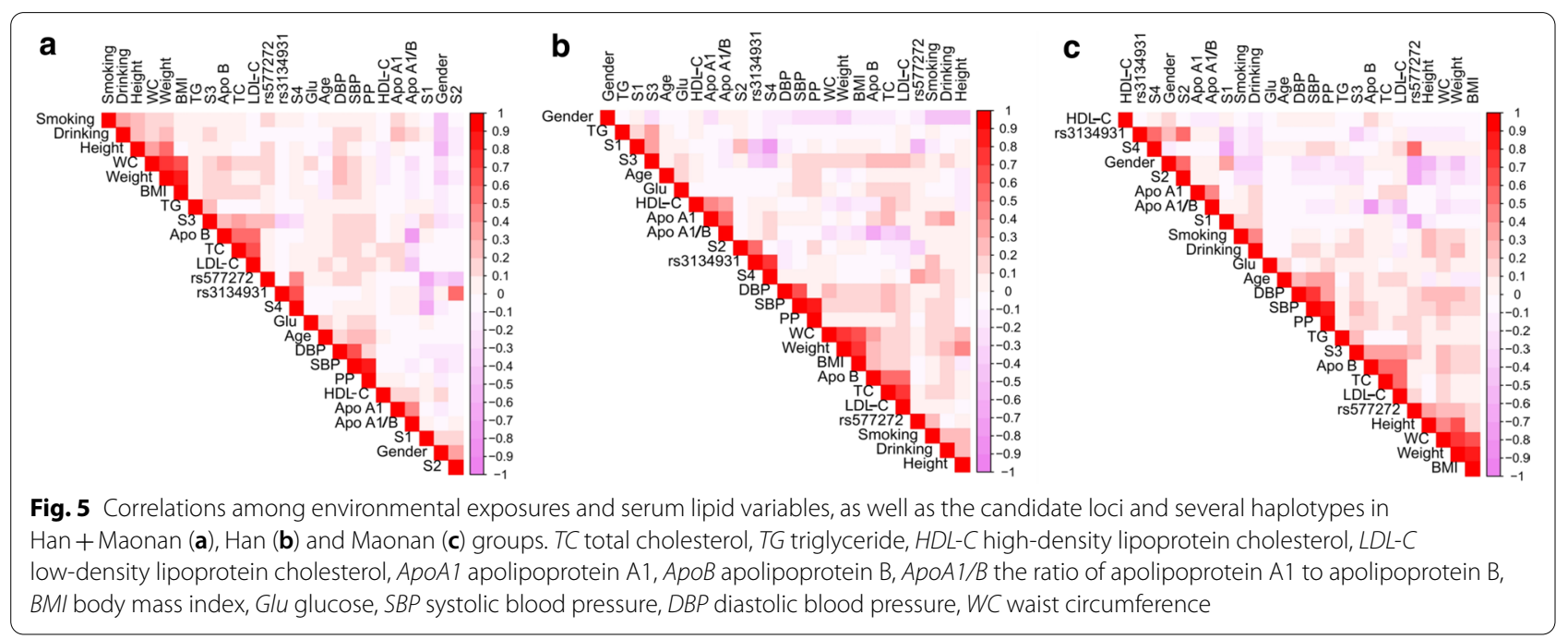

of the SLC44A4 rs577272, NOTCH4 rs3134931 SNPs and serum lipid levels. Haplotypes could explain more changes in serum lipid parameters than any single SNP alone particularly for TC, TG and HDL-C.

\section{Abbreviations}

ANCOVA: Covariance analysis; Apo: Apolipoprotein; BMI: Body mass index; CHD: Coronary heart disease; CRP: C-reactive protein; DNA: Deoxyribonucleic acid; GWAS: Genome-wide association study; HDL-C: High-density lipoprotein cholesterol; HLP: Hyperlipidaemia; HWE: Hardy-Weinberg equilibrium; IS: Ischemic stroke; LD: Linkage disequilibrium; LDL-C: Low-density lipoprotein cholesterol; MI: Myocardial infarction; MPO: Myeloperoxidase; NOTCH4: Neurogenic locus notch homolog protein 4; PCR: Polymerase chain reaction; RFLP: Restriction fragment length polymorphism; SLC44A4: Solute carrier family 44 member 4; SNP: Single nucleotide polymorphisms; T2DM: Type 2 diabetes mellitus; TC: Total cholesterol; TG: Triglyceride.

\section{Acknowledgements}

We are grateful to all the participants of this study and the staff from the Guangxi Key Laboratory Base of Precision Medicine in Cardio-cerebrovascular Disease Control and Prevention.

\section{Authors' contributions}

P-FZ conceived the study, participated in the design, undertook genotyping, performed the statistical analyses, and drafted the manuscript. R-XY conceived the study, participated in the design, carried out the epidemiological survey, collected the samples, and helped to draft the manuscript. PL, L-ZC, Y-ZG, B-LW, C-XL and G-XD carried out the epidemiological survey and collected the samples. All authors read and approved the final manuscript. 


\section{Funding}

This study was supported by the National Natural Science Foundation of China (No. 81460169). There was no role of the funding body in the design of the study and collection, analysis, and interpretation of data and in writing the manuscript.

\section{Availability of data and materials}

The datasets generated during the present study are not publicly available, because detailed genetic information of each participant were included in these materials.

\section{Ethics approval and consent to participate}

All procedures of the investigation were carried out following the rules of the Declaration of Helsinki of 1975 (http://www.wma.net/en/30publicat ions/10policies/b3/), revised in 2008. The study design was approved by the Ethics Committee of the First Affiliated Hospital, Guangxi Medical University (No. Lunshen-2014-KY-Guoji-001, Mar. 7, 2014). Written informed consent was obtained from all participants.

\section{Consent for publication}

Not applicable.

\section{Competing interests}

The authors declare that they have no competing interests.

\section{Author details}

${ }^{1}$ Department of Cardiology, Institute of Cardiovascular Diseases, The First Affiliated Hospital, Guangxi Medical University, Nanning 530021, Guangxi, People's Republic of China. ${ }^{2}$ Guangxi Key Laboratory Base of Precision Medicine in Cardio-Cerebrovascular Disease Control and Prevention, Nanning 530021, Guangxi, People's Republic of China. ${ }^{3}$ Guangxi Clinical Research Center for Cardio-Cerebrovascular Diseases, Nanning 530021, Guangxi, People's Republic of China.

Received: 1 September 2020 Accepted: 3 December 2020

Published online: 14 December 2020

\section{References}

1. Yokokawa H, Yasumura S, Tanno K, Ohsawa M, Onoda T, Itai K, et al. Serum low-density lipoprotein to high-density lipoprotein ratio as a predictor of future acute myocardial infarction among men in a 2.7-year cohort study of a Japanese northern rural population. J Atheroscler Thromb. 2011;18(2):89-98.

2. Finegold JA, Asaria P, Francis DP. Mortality from ischaemic heart disease by country, region, and age: statistics from World Health Organisation and United Nations. Int J Cardiol. 2013;168(2):934-45.

3. Moran A, Forouzanfar M, Sampson U, Chugh S, Feigin V, Mensah G. The epidemiology of cardiovascular diseases in Sub-Saharan Africa: the global burden of diseases, injuries and risk factors 2010 study. Prog Cardiovasc Dis. 2013;56(3):234-9.

4. Pjanic M, Miller CL, Wirka R, Kim JB, DiRenzo DM, Quertermous T. Genetics and genomics of coronary artery disease. Curr Cardiol Rep. 2016;18(10):102

5. Chow CK, Jolly S, Rao-Melacini P, Fox KA, Anand SS, Yusuf S. Association of diet, exercise, and smoking modification with risk of early cardiovascular events after acute coronary syndromes. Circulation. 2010;121(6):750-8.

6. Li Y, Tang K, Zhou K, Wei Z, Zeng Z, He L, et al. Quantitative assessment of the effect of ABCA1 R219K polymorphism on the risk of coronary heart disease. Mol Biol Rep. 2012;39(2):1809-13.

7. Libby P, Theroux P. Pathophysiology of coronary artery disease. Circulation. 2005;111(25):3481-8.

8. Shekelle RB, Shryock AM, Paul O, Lepper M, Stamler J, Liu S, et al. Diet, serum cholesterol, and death from coronary heart disease, The Western Electric study. N Engl J Med. 1981;304(2):65-70.

9. Criqui MH, Heiss G, Cohn R, Cowan LD, Suchindran CM, Bangdiwala S, et al. Plasma triglyceride level and mortality from coronary heart disease. N Engl J Med. 1993;328(17):1220-5.
10. Crouse JR, Parks JS, Schey HM, KahI FR. Studies of low density lipoprotein molecular weight in human beings with coronary artery disease. J Lipid Res. 1985;26(5):566-74

11. Kwiterovich PO Jr, Coresh J, Smith HH, Bachorik PS, Derby CA, Pearson TA. Comparison of the plasma levels of apolipoproteins B and A-1, and other risk factors in men and women with premature coronary artery disease. Am J Cardiol. 1992;69(12):1015-21.

12. Silbernagel $G$, Schottker $B$, Appelbaum S, Scharnagl H, Kleber ME, Grammer TB, et al. High-density lipoprotein cholesterol, coronary artery disease, and cardiovascular mortality. Eur Heart J. 2013;34(46):3563-71.

13. Zheng P-F, Yin R-X, Liu C-X, Deng G-X, Guan Y-Z, Wei B-L. SYNE1-QK1 SNPS, $\mathrm{G} \times \mathrm{G}$ and $\mathrm{G} \times \mathrm{E}$ interactions on the risk of hyperlipidaemia. J Cell Mol Med. 2020;24(10):5772-85.

14. Ligthart S, Vaez A, Hsu YH, Inflammation Working Group of the CC, Pmi Wg XCP, LifeLines Cohort S, et al. Bivariate genome-wide association study identifies novel pleiotropic loci for lipids and inflammation. BMC Genom. 2016;17:443.

15. Reiner AP, Hartiala J, Zeller T, Bis JC, Dupuis J, Fornage M, et al. Genomewide and gene-centric analyses of circulating myeloperoxidase levels in the charge and care consortia. Hum Mol Genet. 2013;22(16):3381-93.

16. Khine HW, Teiber JF, Haley RW, Khera A, Ayers CR, Rohatgi A. Association of the serum myeloperoxidase/high-density lipoprotein particle ratio and incident cardiovascular events in a multi-ethnic population: observations from the Dallas Heart Study. Atherosclerosis. 2017;263:156-62.

17. Delporte C, Van Antwerpen P, Vanhamme L, Roumeguere T, Zouaoui Boudjeltia K. Low-density lipoprotein modified by myeloperoxidase in inflammatory pathways and clinical studies. Mediators Inflamm. 2013;2013:971579.

18. Briot A, Civelek M, Seki A, Hoi K, Mack JJ, Lee SD, et al. Endothelial NOTCH1 is suppressed by circulating lipids and antagonizes inflammation during atherosclerosis. J Exp Med. 2015;212(12):2147-63.

19. Quillard T, Charreau B. Impact of notch signaling on inflammatory responses in cardiovascular disorders. Int J Mol Sci. 2013;14(4):6863-88.

20. Li XM, Ouyang Y, Yang YC, Lin R, Xu HB, Xie ZY, et al. Distribution of food-borne parasitic diseases and dietary habits in human population in Guangxi. Zhongguo Ji Sheng Chong Xue Yu Ji Sheng Chong Bing Za Zhi. 2009;27(2):151-5.

21. Wang Y, Aung L, Tan JY, Yin RX, Hu XJ, Long XJ, et al. Prevalence of dyslipidemia and its risk factors in the Chinese Maonan and Han populations. Int J Clin Exp Pathol. 2016;9:10603-16.

22. Bin Y, Meng EJ, Ya YX, Yin RX, Liu WY, Zhang L, et al. Prevalence, awareness, treatment, control and the risk factors of hypertension in the chinese maonan and han ethnic groups. Int J Clin Exp Med. 2017;10:1209-23.

23. An epidemiological study of cardiovascular and cardiopulmonary disease risk factors in four populations in the People's Republic of China. Baseline report from the P.R.C.-U.S.A. Collaborative Study. People's Republic of China--United States Cardiovascular and Cardiopulmonary Epidemiology Research Group. Circulation. 1992;85(3):1083-96.

24. Guo T, Yin RX, Li H, Wang YM, Wu JZ, Yang DZ. Association of the Trp316Ser variant (rs1801690) near the apolipoprotein H (beta2glycoprotein-I) gene and serum lipid levels. Int J Clin Exp Pathol. 2015;8(6):7291-304.

25. Sun JQ, Yin RX, Shi GY, Shen SW, Chen X, Bin Y, et al. Association of the ARL15 rs6450176 SNP and serum lipid levels in the Jing and Han populations. Int J Clin Exp Pathol. 2015;8(10):12977-94.

26. Guo T, Yin RX, Nie RJ, Chen X, Bin Y, Lin WX. Suppressor of cytokine signaling $3 A+930->G$ (rs4969168) polymorphism is associated with apolipoprotein A1 and low-density lipoprotein cholesterol. Int J Clin Exp Pathol. 2015;8(6):7305-17.

27. Zeng XN, Yin RX, Huang P, Huang KK, Wu J, Guo T, et al. Association of the MLXIPL/TBL2 rs17145738 SNP and serum lipid levels in the Guangxi Mulao and Han populations. Lipids Health Dis. 2013;12:156.

28. Ramazauskiene V. Diet and serum lipids: changes over socio-economic transition period in Lithuanian rural population. BMC Public Health. 2011;11(1):447.

29. 1999 World Health Organization-International Society of Hypertension Guidelines for the Management of Hypertension. Guidelines Sub-Committee. Blood Press Suppl. 1999;1:9-43.

30. Guo T, Yin RX, Lin WX, Wang W, Huang F, Pan SL. Association of the variants and haplotypes in the DOCK7, PCSK9 and GALNT2 genes and the risk of hyperlipidaemia. J Cell Mol Med. 2016;20(2):243-65. 
31. Whitworth JA. 2003 World Health Organization (WHO)/International Society of Hypertension (ISH) statement on management of hypertension. J Hypertens. 2003;21(11):1983-92.

32. Alberti KG, Zimmet PZ. Definition, diagnosis and classification of diabetes mellitus and its complications. Part 1: diagnosis and classification of diabetes mellitus provisional report of a WHO consultation. Diabet Med. 1998;15(7):539-53.

33. Zhou BF. Predictive values of body mass index and waist circumference for risk factors of certain related diseases in Chinese adults-study on optimal cut-off points of body mass index and waist circumference in Chinese adults. Biomed Environ Sci. 2002;15(1):83-96.

34. Zhao S, Guo Y, Sheng Q, Shyr Y. Advanced heat map and clustering analysis using heatmap3. Biomed Res Int. 2014;2014:986048-148.

35. Zhang L, Yin RX, Liu WY, Miao L, Wu DF, Aung LH, et al. Association of methylenetetrahydrofolate reductase C677T polymorphism and serum lipid levels in the Guangxi Bai Ku Yao and Han populations. Lipids Health Dis. 2010;9:123.

36. Ruixing Y, Qiming F, Dezhai Y, Shuquan L, Weixiong L, Shangling P, et al. Comparison of demography, diet, lifestyle, and serum lipid levels between the Guangxi Bai Ku Yao and Han populations. J Lipid Res. 2007:48(12):2673-81.

37. Heller DA, de Faire U, Pedersen NL, Dahlen G, McClearn GE. Genetic and environmental influences on serum lipid levels in twins. N Engl I Med. 1993:328(16):1150-6.

38. Teslovich TM, Musunuru K, Smith AV, Edmondson AC, Stylianou IM, Koseki $\mathrm{M}$, et al. Biological, clinical and population relevance of 95 loci for blood lipids. Nature. 2010;466(7307):707-13.

39. Dehghan A, Dupuis J, Barbalic M, Bis JC, Eiriksdottir G, Lu C, et al. Meta-analysis of genome-wide association studies in $>80000$ subjects identifies multiple loci for C-reactive protein levels. Circulation. 2011;123(7):731-8.

40. Albert MA, Danielson E, Rifai N, Ridker PM. Effect of statin therapy on C-reactive protein levels: the pravastatin inflammation/CRP evaluation (PRINCE): a randomized trial and cohort study. JAMA. 2001;286(1):64-70.

41. Ridker PM, Danielson E, Fonseca FA, Genest J, Gotto AM Jr, Kastelein JJ, et al. Reduction in C-reactive protein and LDL cholesterol and cardiovascular event rates after initiation of rosuvastatin: a prospective study of the JUPITER trial. Lancet. 2009:373(9670):1175-82.

42. Phuah CL, Dave T, Malik R, Raffeld MR, Ayres AM, Goldstein JN, et al. Genetic variants influencing elevated myeloperoxidase levels increase risk of stroke. Brain. 2017;140(10):2663-72.

43. Brennan ML, Penn MS, Van Lente F, Nambi V, Shishehbor MH, Aviles RJ, et al. Prognostic value of myeloperoxidase in patients with chest pain. $N$ Engl J Med. 2003;349(17):1595-604.

44. Baldus S, Heeschen C, Meinertz T, Zeiher AM, Eiserich JP, Munzel T, et al. Myeloperoxidase serum levels predict risk in patients with acute coronary syndromes. Circulation. 2003;108(12):1440-5.

45. Tang WH, Tong W, Troughton RW, Martin MG, Shrestha K, Borowski A, et al. Prognostic value and echocardiographic determinants of plasma myeloperoxidase levels in chronic heart failure. J Am Coll Cardiol. 2007:49(24):2364-70.

46. Karakas M, Koenig W. Myeloperoxidase production by macrophage and risk of atherosclerosis. Curr Atheroscler Rep. 2012;14(3):277-83.

47. Schnabel RB, Lunetta KL, Larson MG, Dupuis J, Lipinska I, Rong J, et al. The relation of genetic and environmental factors to systemic inflammatory biomarker concentrations. Circ Cardiovasc Genet. 2009;2(3):229-37.

48. Walker AE, Seibert SM, Donato AJ, Pierce GL, Seals DR. Vascular endothelial function is related to white blood cell count and myeloperoxidase among healthy middle-aged and older adults. Hypertension. 2010:55(2):363-9.
49. Tang WH, WU Y, Nicholls SJ, Hazen SL. Plasma myeloperoxidase predicts incident cardiovascular risks in stable patients undergoing medical management for coronary artery disease. Clin Chem. 2011;57(1):33-9.

50. Nicholls SJ, Hazen SL. Myeloperoxidase and cardiovascular disease. Arterioscler Thromb Vasc Biol. 2005;25(6):1102-11.

51. Nicholls SJ, Zheng L, Hazen SL. Formation of dysfunctional highdensity lipoprotein by myeloperoxidase. Trends Cardiovasc Med. 2005;15(6):212-9.

52. Nicholls SJ, Hazen SL. Myeloperoxidase, modified lipoproteins, and atherogenesis. J Lipid Res. 2009;50(Suppl):S346-51.

53. Valente EA, Sheehy ME, Avila JJ, Gutierres JA, Delmonico MJ, Lofgren IE. The effect of the addition of resistance training to a dietary education intervention on apolipoproteins and diet quality in overweight and obese older adults. Clin Interv Aging. 2011;6:235-41.

54. Mansfield E, McPherson R, Koski KG. Diet and waist-to-hip ratio: important predictors of lipoprotein levels in sedentary and active young men with no evidence of cardiovascular disease. J Am Diet Assoc. 1999:99(11):1373-9.

55. Joffe YT, Collins M, Goedecke JH. The relationship between dietary fatty acids and inflammatory genes on the obese phenotype and serum lipids. Nutrients. 2013;5(5):1672-705.

56. Guo T, Yin R-X, Pan L, Yang S, Miao L, Huang F. Integrative variants, haplotypes and diplotypes of the CAPN3 and FRMD5 genes and several environmental exposures associate with serum lipid variables. Sci Rep. 2017;7:45119-219.

57. Ruixing $Y$, Jinzhen $W$, Yaoheng H, Jing T, Hai W, Muyan L, et al. Associations of diet and lifestyle with hyperlipidemia for middle-aged and elderly persons among the Guangxi Bai Ku Yao and Han populations. J Am Diet Assoc. 2008;108(6):970-6.

58. Lottenberg AM, Afonso Mda S, Lavrador MS, Machado RM, Nakandakare ER. The role of dietary fatty acids in the pathology of metabolic syndrome. J Nutr Biochem. 2012;23(9):1027-40.

59. Rimm EB, Williams P, Fosher K, Criqui M, Stampfer MJ. Moderate alcohol intake and lower risk of coronary heart disease: meta-analysis of effects on lipids and haemostatic factors. BMJ. 1999;319(7224):1523-8.

60. Ruixing Y, Shangling P, Hong C, Hanjun Y, Hai W, Yuming C, et al. Diet, alcohol consumption, and serum lipid levels of the middle-aged and elderly in the Guangxi Bai Ku Yao and Han populations. Alcohol. 2008;42(3):219-29.

61. Pai JK, Mukamal KJ, Rimm EB. Long-term alcohol consumption in relation to all-cause and cardiovascular mortality among survivors of myocardial infarction: the Health Professionals Follow-up Study. Eur Heart J. 2012;33(13):1598-605.

62. Rao ChS, Subash YE. The effect of chronic tobacco smoking and chewing on the lipid profile. J Clin Diagn Res. 2013;7(1):31-4.

63. Maeda K, Noguchi Y, Fukui T. The effects of cessation from cigarette smoking on the lipid and lipoprotein profiles: a meta-analysis. Prev Med. 2003;37(4):283-90.

\section{Publisher's Note}

Springer Nature remains neutral with regard to jurisdictional claims in published maps and institutional affiliations.

Ready to submit your research? Choose BMC and benefit from:

- fast, convenient online submission

- thorough peer review by experienced researchers in your field

- rapid publication on acceptance

- support for research data, including large and complex data types

- gold Open Access which fosters wider collaboration and increased citations

- maximum visibility for your research: over $100 \mathrm{M}$ website views per year

At BMC, research is always in progress.

Learn more biomedcentral.com/submissions 